\title{
The Modulation of the Subtropical and Extratropical Atmosphere in the Pacific Basin in Response to the Madden-Julian Oscillation
}

\author{
Richard W. MoOre,* Olivia Martius, And ThOMAS SPEngler ${ }^{+}$ \\ Institute for Atmospheric and Climate Science, ETH-Zürich, Zürich, Switzerland
}

(Manuscript received 18 August 2009, in final form 19 November 2009)

\begin{abstract}
The 40-yr ECMWF Re-Analysis (ERA-40) data are combined with a number of novel climatologies to conduct a comprehensive examination of the response of the subtropical and extratropical atmosphere over the Pacific basin to an evolving Madden-Julian oscillation (MJO) event. The adopted approach constitutes a symbiosis of a climatological analysis during the Northern Hemisphere winter from 1979 to 2002 and a case study analysis of a distinct MJO event that occurred in January-February 1993. The former is designed to obtain the general characteristics observed during a composite MJO life cycle, while the latter is used to provide insight into the instantaneous mechanisms responsible for the observed composite evolution.

A primary component of the study involves the diagnosis of anomalous wave breaking activity in response to $\mathrm{MJO}$ forcing in the form of tropical convection and/or upper-level divergence. Wave breaking events are separated by their characteristic life cycles: LC1 (anticyclonic) and LC2 (cyclonic) events. Statistically significant anomalies in wave breaking activity are found to be prevalent during the composite MJO event. Furthermore, the dynamical distinction between LC1 and LC2 wave breaking is useful in that the two different characteristic life cycles exhibit significantly different anomalous behavior during the MJO.

Statistically significant variability is also identified in both the subtropical and extratropical flow and atmospheric blocking and surface cyclone frequency. These data, taken in conjunction with the observed evolution of the 1993 MJO event, provide a relatively coherent picture of the response of the atmosphere to MJO forcing. A schematic representation of the evolution is presented.
\end{abstract}

\section{Introduction}

The Madden-Julian oscillation (MJO) represents a largescale coupled pattern between tropical deep convection and atmospheric circulation. It is known to be the dominant source of intraseasonal variability in the tropics (Madden and Julian 1972, 1994; Zhang 2005). Its impacts are, however, not limited to tropical latitudes. Forcing by the MJO, in the form of latent heat release associated with tropical convection, can have a profound impact on the subtropical and extratropical flow in both hemispheres: numerous studies have identified a significant

\footnotetext{
* Current affiliation: Department of Meteorology, Naval Postgraduate School, Monterey, California.

+ Current affiliation: Atmospheric and Oceanic Sciences Program, Princeton University, Princeton, New Jersey.
}

Corresponding author address: Richard Moore, Department of Meteorology, Naval Postgraduate School, Monterey, CA 93943. E-mail: rwmoor1@nps.edu correlation between different phases of the MJO (i.e., specific tropical longitudes of anomalous convection and/ or upper-level divergence) and subtropical and extratropical flow anomalies (e.g., Knutson and Weickmann 1987; Ferranti et al. 1990; Kiladis and Weickmann 1992; Hendon and Salby 1994; Higgins and Mo 1997; Matthews et al. 2004). Given the complexity of the problem, however, it has proved difficult to unequivocally determine causality or, more specifically, the precise dynamical mechanisms linking the tropical convection and the observed flow anomalies that can occur on a global scale.

Useful insight can be gained by examining the results from simplified modeling studies of the response of the tropical atmosphere to anomalous mass sources and sinks. Utilizing a two-layer equatorial shallow-water model, Matsuno (1966) and Gill (1980) found that mass sources or sinks serve as a wave source for equatorially trapped waves. These mass sources (sinks) can be argued to be equivalent to cooling (heating) in a baroclinic model and, in this way, the results of Matsuno and Gill illustrate how 
tropical convection can serve as a wave source for poleward propagating, planetary-scale Rossby waves in both hemispheres. The so-called Matsuno-Gill response to tropical convection predicts the formation of an upperlevel anticyclone to the northwest and southwest of sustained, anomalous tropical convection. This interpretation is consistent with the idealized full-physics atmospheric model results of Barlow et al. (2007). In this way, the MJO convection can directly impact the subtropical and extratropical flow.

The large-scale, observed response to the MJO is, however, not limited to the Matsuno-Gill pattern. It has been suggested in previous work that the MJO extratropical circulation anomalies result not only from the direct Rossby wave response (Simmons 1982; Jin and Hoskins 1995) but also from the existence of an extratropical mode in the jet exit regions in the Pacific and Atlantic Oceans (e.g., Simmons et al. 1983; Schubert and Park 1991; Hsu 1996; Matthews et al. 2004; Mori and Watanabe 2008). In the Pacific basin a barotropic normalmode analysis reveals that the leading unstable mode based on the time mean winter flow resembles the PacificNorth American (PNA) teleconnection pattern (Simmons et al. 1983). It is argued that perturbations projecting onto this mode extract energy from the mean extratropical flow via barotropic conversion. Hsu (1996) shows that this mode can be excited in the presence of tropical heating emitting Rossby waves into the extratropics. However, he regards the growth of the mode as being only indirectly related to the tropical heating since the internal midlatitude dynamics will dominate the later evolution far removed from the tropics.

An alternative view on the instability in the Pacific basin is presented by Swanson (2000). Reducing the midlatitude flow to a binary distribution of potential vorticity (i.e., contour dynamics of a single jet), the author illustrates that wave energy will pile up at the jet exit region yielding unstable growth that resembles PNA-like variability patterns.

In practical terms, the observed subtropical and extratropical anomalies associated with the MJO are synonymous with significant variability of the amplitude and location of the midlatitude jet (hereafter jet). As such, the MJO also impacts the propagation characteristics of waves along the jet (Matthews and Kiladis 1999b) and the behavior of tropopause-level wave breaking. In conjunction, these effects may serve an important role in determining the evolving structure of MJO anomalies: the divergence of momentum fluxes associated with a breaking wave can have a significant feedback on the mean flow (Hoskins et al. 1983; Magnusdottir and Haynes 1996). The precise nature of the feedback is largely determined by the life cycle of the wave breaking event (cyclonic or anticyclonic), which, in turn, is intimately connected to the position and asymmetry of the jet (e.g., Thorncroft et al. 1993; Akahori and Yoden 1997; Riviere 2009).

Large-scale flow anomalies (so-called annular modes or teleconnection patterns; e.g., the North Atlantic Oscillation, PNA, and zonal index) are usually related to changes in the orientation and location of the jet (Vallis and Gerber 2008). There is a growing appreciation in the scientific community that their formation and/or maintenance essentially results from breaking waves and their feedback on the mean flow (e.g., Franzke et al. 2004; Benedict et al. 2004; Riviere and Orlanski 2007; Martius et al. 2007; Strong and Magnusdottir 2008; Woollings et al. 2008; Vallis and Gerber 2008). In light of these findings, it is relevant to question the subtleties of cause and effect between the subtropical and extratropical MJO response and wave breaking processes.

This is a difficult issue to directly address. However, a necessary and important first step is to accurately characterize anomalous wave breaking behavior during the MJO life cycle, something that to our knowledge has heretofore not been accomplished. It is therefore a primary goal of this work to diagnose the time-evolving characteristics of wave breaking over the Pacific basin during the MJO life cycle.

While this information alone would be both novel and useful, the overarching goal of this work is to provide a comprehensive analysis of the observed response of the subtropical and extratropical atmosphere to MJO forcing. To do so, it is necessary to examine the anomalous wave breaking behavior in the context of the previously reported, observed changes in the upper- and low-level flow field. It is believed that such a study will provide a unique and dynamically meaningful contribution to the current understanding of the subtropical and extratropical response to the MJO.

The outline of this manuscript is as follows. Section 2 will present the data and methodology employed. Section 3 will describe the climatological response of the subtropical and extratropical flow, wave breaking, and surface weather to the MJO during the Northern Hemisphere winter. To further elucidate the climatological results, a distinct MJO event that occurred in January and February 1993 will be examined in detail in section 4. A discussion of the study results, including the presentation of a schematic representation of the study conclusions, is provided in section 5 .

\section{Ingredients of the diagnosis}

The primary source of data for this study is the 40-yr European Centre for Medium-Range Weather Forecasts (ECMWF) Re-Analysis data (ERA-40; Uppala 
et al. 2006). The data are available 4 times daily with $1^{\circ}$ horizontal resolution and 60 vertical levels. In addition to the typical meteorological fields, a number of novel climatologies constructed from ERA-40 data are used herein. They compose the behavior of synoptic-scale wave breaking, atmospheric blocks, and surface cyclones, respectively, over the ERA-40 time period. All three phenomena are directly related to synoptic-scale weather.

Synoptic-scale breaking waves can be viewed as elongated, meridionally oriented stratospheric intrusions of high potential vorticity (PV) air into the troposphere (Appenzeller and Davies 1992). They represent the irreversible deformation of material contours at the tropopause level (McIntyre and Palmer 1983). The stratospheric intrusions (referred to as PV streamers) are identified using the objective method described in Wernli and Sprenger (2007). Their algorithm searches for synoptic-scale structures on the dynamical tropopause on middle world isentropic surfaces that have a narrow connection to the main stratospheric body of air (less than $1000 \mathrm{~km}$ ). A further dynamical distinction of wave breaking events is based on the characteristic life cycle of baroclinic waves [cyclonic (LC2) and anticyclonic (LC1) patterns; Thorncroft et al. (1993)]. Cyclonic and anticyclonic PV streamers are distinguished using the angle between the zonal direction and the main axis of the streamers. If this angle is less (more) than $75^{\circ}\left(105^{\circ}\right)$, the streamer is identified as an LC1 (LC2) type streamer. A detailed description of the methodology including a sensitivity analysis is given in Martius et al. (2007).

Atmospheric blocking is characterized by a disruption in the midlatitude westerlies due to the presence of a quasi-stationary high pressure system that persists for at least several days (e.g., Rex 1950; Dole and Gordon 1983; Lupo and Smith 1995; Schwierz et al. 2004). CrociMaspoli et al. (2007) present a blocking climatology in which the block is viewed as a large-amplitude, longlasting negative PV anomaly in the immediate vicinity of, and below, the tropopause. In their study, vertically averaged (between 500 and $150 \mathrm{hPa}$ ) PV anomalies are identified at each 6-hourly time step, and a tracking routine is used to diagnose the entire PV anomaly life cycle. If a vertically averaged PV anomaly satisfies a threshold of -1.3 PV units for a time period of at least 5 days, the anomaly is identified as an atmospheric block.

Wernli and Schwierz (2006) derived a climatology of extratropical cyclones from gridded sea level pressure (SLP) ERA-40 data. In their algorithm, a cyclone is defined as the finite area that surrounds a local SLP minimum. A grid point is considered a cyclone center if its SLP value is less than the SLP value of the surrounding eight grid points. The cyclone field associated with each cyclone center is defined by the area enclosed by the outermost closed SLP contour that encloses the SLP minimum. At each time step, a value of one (zero) is attributed to a grid point inside (outside) the identified cyclone field. Cyclone identification is performed at each individual time instant. Cyclone frequency, defined as the percentage of time a cyclone is present at a specific grid point, is then determined by simple time averaging.

All three of these novel climatologies represent instantaneous, 6-hourly data regarding the presence or absence of the respective feature at each grid point. The existence of such data provides a unique opportunity, allowing for a direct comparison between these weather-related features and both the state of the MJO and the quantitative values of relevant meteorological parameters that describe the state of the subtropical and extratropical atmosphere.

To determine the presence of an MJO and the respective phase of an MJO event, daily MJO indices based on the 200-hPa velocity potential are acquired from the Climate Prediction Center (CPC; more information is available online at www.cpc.noaa.gov/products/precip/ CWlink/daily_mjo_index/mjo_index.html). To construct the indices, an extended empirical orthogonal function (EEOF) analysis is applied to the pentad velocity potential for ENSO-neutral and weak ENSO winters (NovemberApril) during 1979-2000. Strong ENSO events are removed from the analysis to filter out the low-frequency signal associated with ENSO that would otherwise erroneously impact the intraseasonal MJO EEOF analysis (J. Gottschalck, CPC, 2009, personal communication). The first EEOF is composed of 10 time-lagged patterns, with a lag of 5 days between patterns. Ten MJO indices are then constructed by regressing the daily $200-\mathrm{hPa}$ velocity potential anomalies onto the 10 time-lagged patterns of the first EEOF. Each of the 10 indices, therefore, provides information regarding tropical (equatorward of $\left.30^{\circ}\right)$ upper-level divergence for a specific longitude $\left(80^{\circ} \mathrm{E}\right.$, $100^{\circ} \mathrm{E}, 120^{\circ} \mathrm{E}, 140^{\circ} \mathrm{E}, 160^{\circ} \mathrm{E}, 120^{\circ} \mathrm{W}, 40^{\circ} \mathrm{W}, 10^{\circ} \mathrm{W}, 20^{\circ} \mathrm{E}$, and $70^{\circ} \mathrm{E}$ for indices $1-10$, respectively). The time-lagged nature of the MJO index data allows for the documentation of the temporal evolution of the subtropical and extratropical response to an evolving MJO event.

The data for each MJO index are separated into terciles. The upper, middle, and lower terciles represent suppressed, neutral, and enhanced upper-level divergence, respectively. We equate days with $\mathrm{MJO}$ index values in the lower tercile with an active MJO event, taking enhanced upper-level divergence as a sign of rising motion associated with the MJO. Given this distinction, we subsequently construct the Northern Hemisphere winter [December-January-February (DJF)] climatological response of the subtropical and extratropical atmosphere to tropical MJO forcing by calculating a time average for 
each index over the 1979-2002 time period. This subset of the ERA-40 period is chosen because of the availability of satellite data from 1979 onward. Anomalies from "mean" conditions are created by subtracting the DJF average over the same time period.

To determine the statistical significance of the results, a Monte Carlo approach is incorporated [see Scherrer et al. (2006) for a complete description of the methodology]. Six hundred randomly generated MJO index time series are created taking the autocorrelation of the MJO indices into account. For each of the 600 time series, climatological composites are created as above and are then compared with the observed climatological distribution. In this way, the robustness of the observed response can be tested. All anomaly data presented herein are significant at or above the $95 \%$ confidence level.

The climatological analysis is a core component of this work. However, there is an important caveat that comes with such a database. The time-mean structure of the atmosphere is, of course, composed of the average characteristics of the instantaneous structure. It is readily apparent when viewing this "instantaneous structure" that it can and does exhibit significant variability over short time scales. It often bears only a scant resemblance to the time-mean structure. Therefore, one must exercise caution when using the time-mean structure of the atmosphere to explain the instantaneous physical processes at work in the atmosphere.

This very reason motivates the symbiosis of climatological and representative case study analyses. For the latter, an MJO event that occurred in January and February 1993 has been chosen. At 6-hourly time intervals, ERA-40 data are analyzed. To investigate wave-breaking activity, the 2-PV unit (PVU) isoline on isentropic surfaces (310-350 K, interval of $10 \mathrm{~K}$ ) are examined. In addition, daily mean outgoing longwave radiation (OLR) data from the CPC (Liebmann and Smith 1996) and the 200-hPa streamfunction anomaly (defined as the difference from the average streamfunction over the MJO event) are used to represent clouds/precipitation and upper-level flow anomalies, respectively.

\section{Climatological response to $\mathrm{MJO}$ forcing}

Both the location and type of wave breaking events are intimately connected to the structure of the tropopauselevel flow field (i.e., the jet). The observed variability of the jet during the MJO life cycle leads to an underlying hypothesis of this study: wave breaking behavior must also exhibit significant variability during an MJO event.

This section provides an in depth analysis of the climatological response of the subtropical and extratropical atmosphere to $\mathrm{MJO}$ forcing. Prior to investigating the above hypothesis, it is useful to present the large-scale subtropical and extratropical flow anomalies that are observed during the composite MJO over the DJF 1979-2002 period. Subsequently, the climatology of wave breaking behavior is presented. Finally, the variability of some more conventional "weather" parameters is discussed.

\section{a. Flow variations}

\section{1) UPPER-LEVEL JET}

The 250-hPa total wind speed DJF average and the average and anomaly fields for select MJO indices are presented in Fig. 1. There are a number of important features of note that can be gleaned from Fig. 1 .

The first represents a direct dynamical response to the tropical convection. When the MJO is convectively active over the Eastern Hemisphere (roughly MJO indices $1-5,10)$, there is a statistically significant northward shift and increase in the strength of the jet core near the longitude of the tropical MJO convection (e.g., Yang and Webster 1990; Matthews and Kiladis 1999a; Figs. 1b-d). This observation is consistent with the analytical solution outlined by Matsuno (1966) and Gill (1980) and the idealized modeling study of Barlow et al. (2007), whereby Rossby waves generated by the tropical heating take the form of an upper-level anticyclone to the northwest of the area of maximum heating. The enhanced meridional temperature and PV gradients on the northern periphery of the upper-level anticyclone are concomitant with an acceleration of the jet and, via this mechanism, the maximum positive jet anomaly is observed to propagate eastward in conjunction with the MJO convection (e.g., Schubert and Park 1991). Furthermore, from thermalwind balance, the increased vertical wind shear associated with the strengthened tropopause-level jet implies an increase in local horizontal baroclinicity through some depth of the troposphere.

Conversely, when tropical convection is suppressed in the Eastern Hemisphere (MJO indices 6-9; Figs. 1e,f), jet anomalies of the opposite sign are observed: there is a southward shift and weakening of the jet when compared with the climatological mean. That this must be true is intuitive from both a statistical as well as a dynamical point of view. The climatological mean jet is comprised of the average jet characteristics over the entire MJO life cycle. Therefore, a northward shift and increased strength in the jet must be balanced by a southward shift and decreased strength during the composite MJO. From a dynamical perspective, the MJO convection and the dynamical forcing it provides is by definition a propagating feature. While present, the tropical convection serves to locally shift to the north and enhance the jet. In its absence, 
(a)

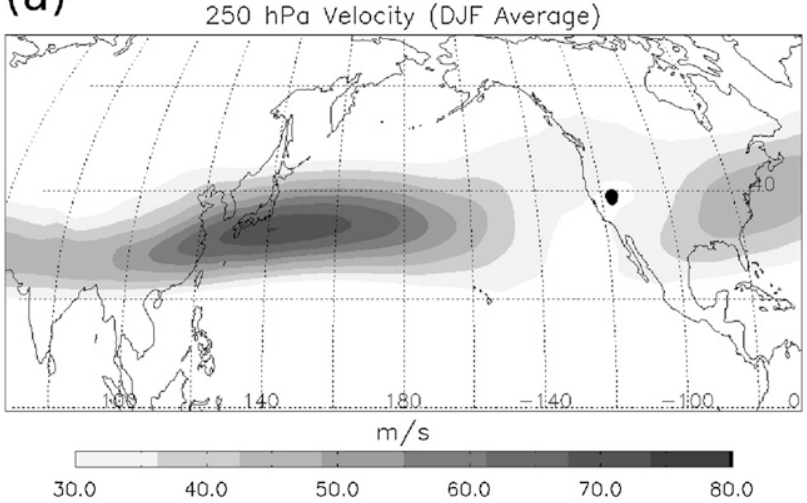

(c)

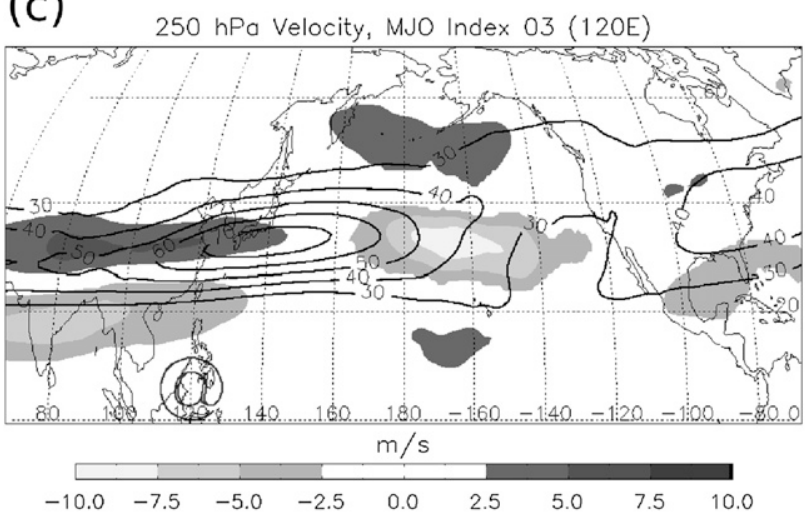

(e)

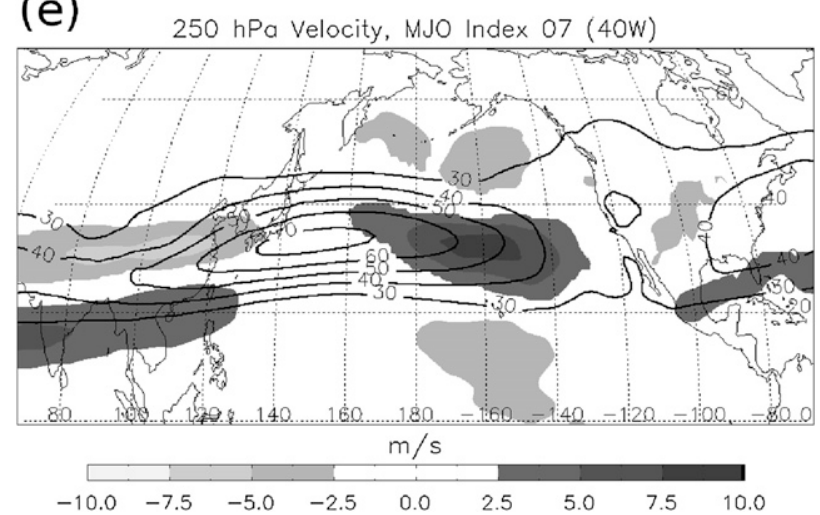

(b)

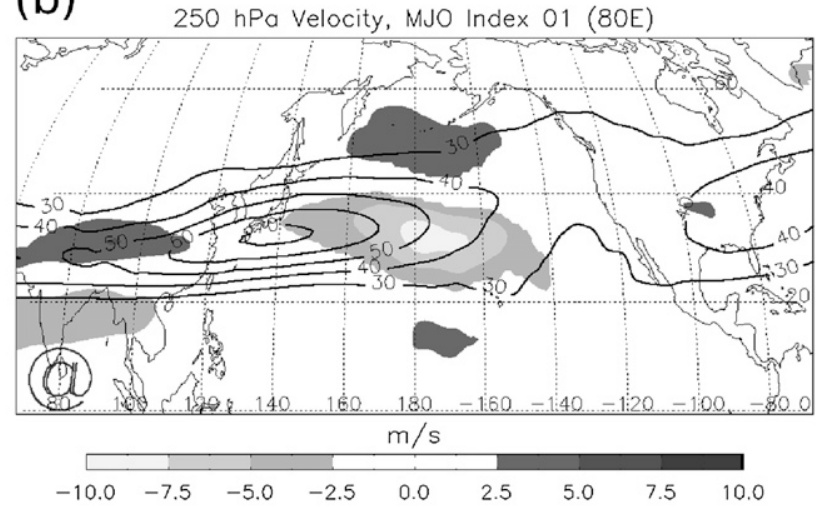

(d)

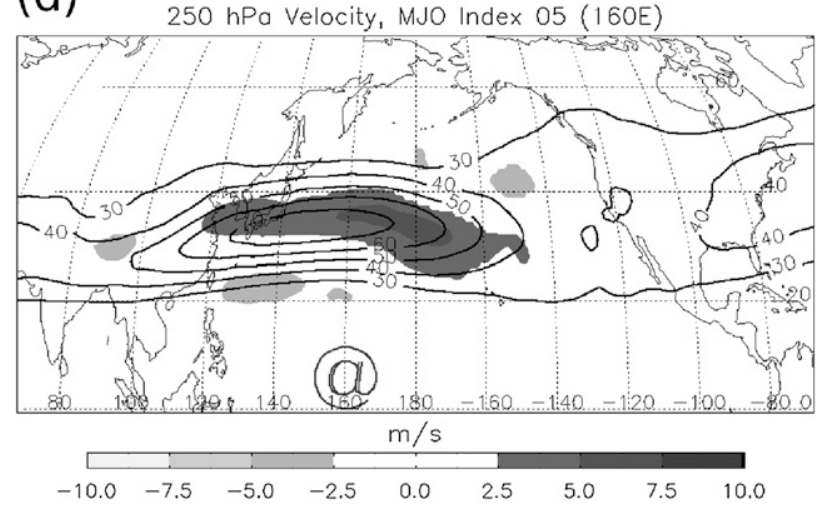

(f)

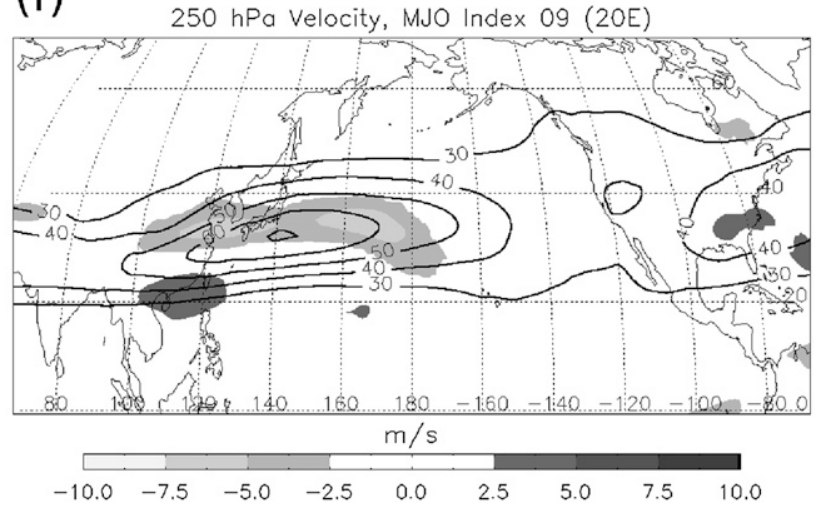

FIG. 1. The 250-hPa total wind speed ( $\mathrm{m} \mathrm{s}^{-1}$ ): (a) 1979-2002 DJF average; and average (black, contour interval $10 \mathrm{~m} \mathrm{~s}^{-1} \mathrm{beginning} \mathrm{at}^{-1}$ $30 \mathrm{~m} \mathrm{~s}^{-1}$ ) and anomaly from DJF average (shading; statistically significant at the $95 \%$ confidence level) for (b) MJO index 1 , (c) MJO index 3, (d) MJO index 5, (e) MJO index 7, and (f) MJO index 9. The '@' symbol represents the center longitude of MJO convection and/or upper-level divergence.

the forcing mechanism is removed and the jet must shift to the south and be weaker when compared to the mean.

While these arguments may appear somewhat obtuse, the observed changes in the Eastern Hemisphere do have a profound impact on both wave breaking dynamics and synoptic-scale weather. A more northerly (southerly) jet, in comparison to the climatological mean, is predisposed to LC1 (LC2) wave breaking (e.g., Akahori and
Yoden 1997; Riviere 2009). This issue will be examined in more detail shortly.

In the central and eastern North Pacific, the breadth and strength of the $250-\mathrm{hPa}$ jet exhibit significant variability during the composite MJO life cycle. The timemean jet appears both broad and weak when MJO convection is in the Indian Ocean and the warm pool region (Figs. 1b,c) and, conversely, narrow and strong when the 
MJO has translated east of the date line (Fig. 1e). Taken together, these anomalies describe a jet that is retracted to the west during the early phases of the MJO and subsequently extended eastward into the central Pacific.

To first order, these results are valid in that the jet maximum has a tendency to be farther to the west during the early phases of the MJO. However, an examination of the instantaneous jet for specific MJO events illustrates that the broad and weak structure of the jet in the central and eastern North Pacific is at least in part due to the large variability in the position of the jet. During this time (MJO indices 1-3), there is a higher frequency of a double jet structure: a relatively strong midlatitude jet in the western North Pacific and a branch of the subtropical jet in the central or eastern North Pacific. This characteristic jet structure is predominantly associated with LC1 wave breaking, an issue that will be examined more closely in the MJO case study analysis where it is possible to examine the instantaneous jet structure and its connection with wave breaking (see section 4).

A final feature that is quite striking when examining Fig. 1 is the relatively quick transition between two qualitatively opposite anomaly patterns that occurs during the composite MJO event. The transitions occur during the roughly 5-10-day period closest to MJO indices 5 and 9. This is a robust feature of the evolution of all anomaly fields. It is a goal of this work to provide some insight into the dynamical processes responsible for this feature.

\section{2) 500-HPA HEIGHT}

Average and anomaly plots of the $500-\mathrm{hPa}$ height are presented in Fig. 2. The results are generally consistent with those of the 250-hPa jet evolution: when the jet is retracted to the west over eastern Asia (extended to the east over the central Pacific), a positive (negative) anomaly is present in the central North Pacific 500-hPa height field. As with the jet anomalies, a relatively quick transition between the two states is observed. Similar to previous results, there is a qualitative similarity to the PNA pattern during specific MJO phases: a negative (positive) PNA-like pattern is observed during MJO phase 3 (7). These results are also very similar to those of Lin and Brunet (2009; see their Fig. 6) who calculated lagged composite of the 500-hPa geopotential height for various MJO phases.

\section{b. Wave breaking}

The DJF average distribution and the composite and anomaly from the average for specific phases of the MJO are presented for $\mathrm{LC} 1$ (anticyclonic) wave breaking on the 330-K isentropic surface and LC2 (cyclonic) wave breaking on the 310-K isentropic surface in Figs. 3 and 4, respectively. LC1 and LC2 wave breaking are presented on different isentropic surfaces because of their proclivity to be the dominant form of wave breaking on higher and lower isentropic surfaces, respectively (see Fig. 5 in Martius et al. 2007).

It is useful to briefly discuss the general characteristics of wave breaking and its relationship with the jet in the Pacific basin during the Northern Hemisphere winter (Figs. 3a and 4a; Martius et al. 2007). For a clear visualization of the zonal-mean relationship between the DJF wind velocity, pressure, potential temperature, and the dynamical tropopause in the Pacific basin, see Fig. 2b in Martius et al. (2007). Wave breaking is most common in the central and eastern Pacific in the climatological jet exit region. LC1 wave breaking is predominant on higher isentropic surfaces and farther to the south (Fig. 3a). It is favored when the jet is shifted northward with respect to the climatological mean (Akahori and Yoden 1997; Riviere 2009). In regions of frequent LC1 wave breaking, the jet appears broad and weak in the climatological mean (Esler and Haynes 1999). Conversely, LC2 wave breaking is more common on lower isentropic surfaces and farther to the north (Fig. 4a). It is favored when the jet is shifted to the south (Akahori and Yoden 1997; Riviere 2009), and the climatological mean jet appears strong and narrow in regions of frequent LC2 wave breaking (Esler and Haynes 1999).

Momentum fluxes associated with wave breaking events can feed back on the structure of the mean flow. It has been shown that the divergence of momentum fluxes associated with LC1 and LC2 wave breaking serve to shift the latitude of the jet poleward and equatorward, respectively (Edmon et al. 1980; Magnusdottir and Haynes 1996; Riviere and Orlanski 2007; Riviere 2009).

A number of important points can be gleaned from the composite/anomaly fields seen in Figs. 3 and 4: (i) statistically significant anomalies in wave breaking activity are prevalent during the composite MJO event, primarily but not limited to the central and eastern North Pacific where wave breaking is climatologically most frequent; (ii) the dynamical distinction between LC1 and LC2 wave breaking is useful in that the two different characteristic life cycles exhibit different anomalous behavior during the MJO; and (iii) as observed in the subtropical and extratropical flow anomalies, there is a strong anticorrelation found in the maximum observed anomalies in the central and eastern Pacific, with a fairly rapid transition roughly occurring during MJO phases 5 and 9.

More specifically, LC1 (LC2) wave breaking occurs significantly more (less) frequently in the central and eastern Pacific when MJO convection is present in the 
(a)

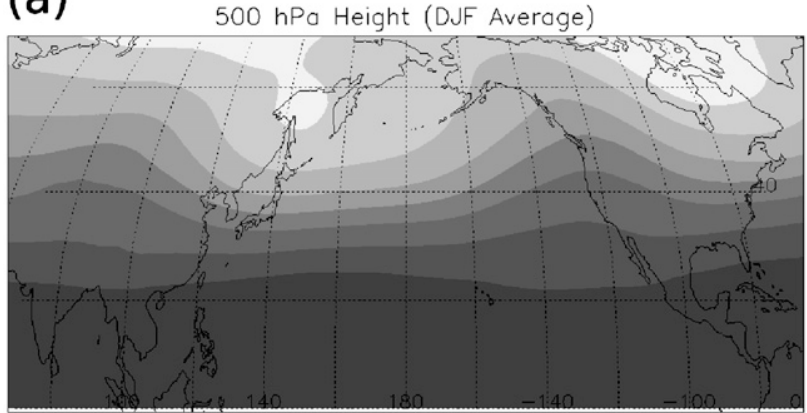

m

(c)
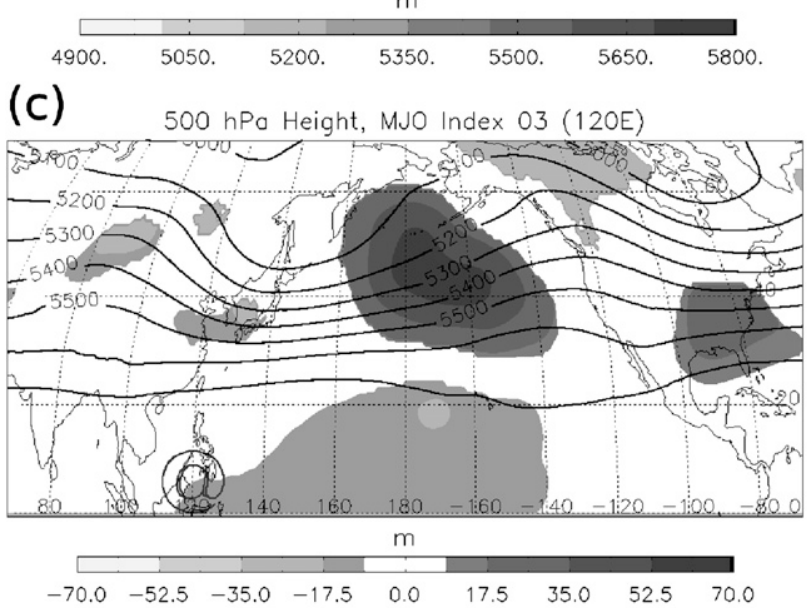

(e)

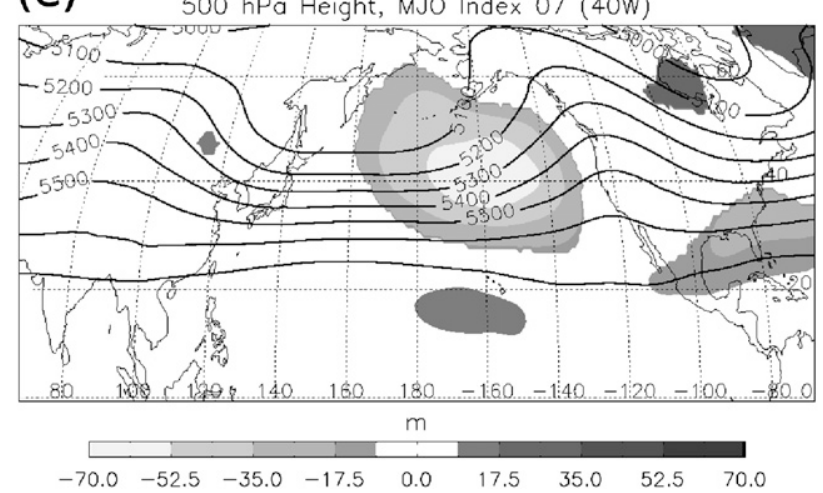

(b)

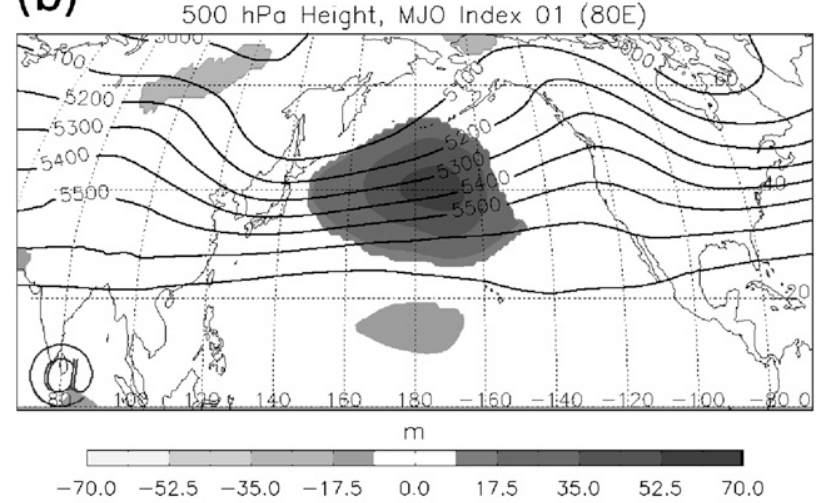

(d)

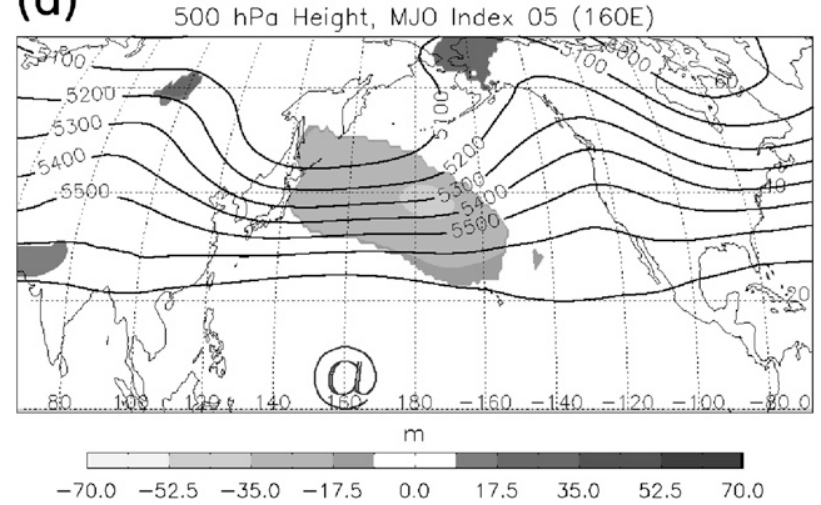

(f)

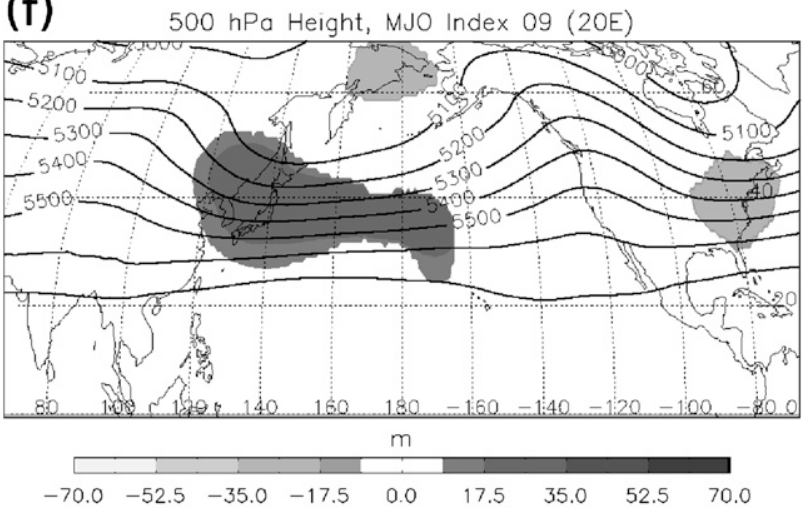

FIG. 2. As in Fig. 1, but for 500-hPa height (m). Contour interval is $100 \mathrm{~m}$.

Indian Ocean and the warm pool region [MJO indices 1-4, 10; Figs. 3b,c (Figs. 4b,c)], with a distinct maximum (minimum) during MJO index 3. During this time, the time-mean jet is retracted westward and shifted to the north. The opposite is true when MJO convection has ceased and the upper-level divergence associated with the MJO has progressed east of the date line [MJO indices 6-8, maximum during index 7; Fig. 3e (Fig. 4e)] and the time-mean jet is extended across the Central Pacific and shifted southward.

Perhaps less obvious, but nonetheless a robust signature of both the MJO composites and individual MJO events that were examined (see, e.g., section 4), is enhanced LC1 wave breaking in the subtropical central and eastern Pacific during MJO indices 1-3 [Figs. 3b,c; the signal is more prevalent on higher isentropic surfaces (not shown)] and enhanced LC2 wave breaking in the western and central North Pacific during MJO indices 3-5 (Figs. 4c,d). Often multiple wave breaking events, of both types, occur with the subsequent event occurring to the east of the previous event.

These observed anomalies are generally consistent with the subtropical and extratropical flow anomalies. The LC1 wave breaking observed over the central Pacific 
(a)

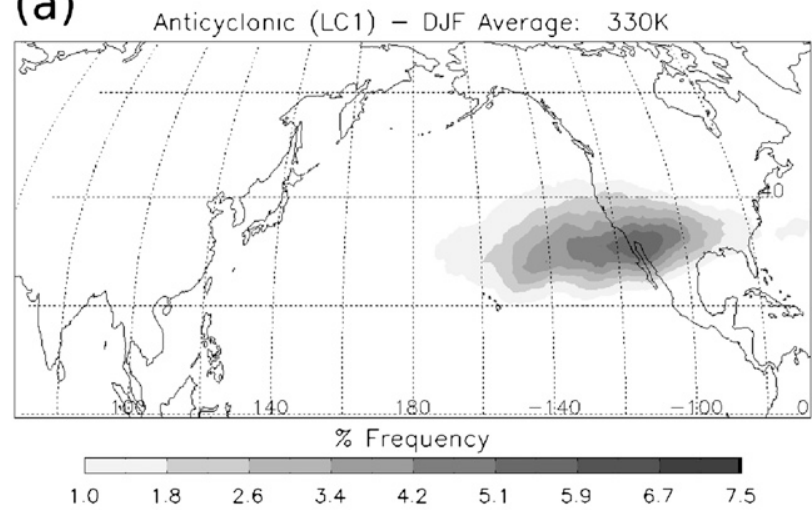

(c)

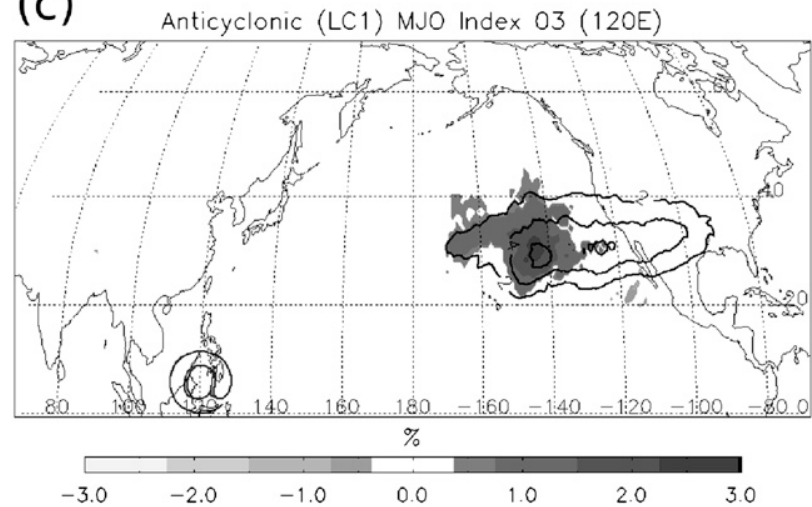

(e)

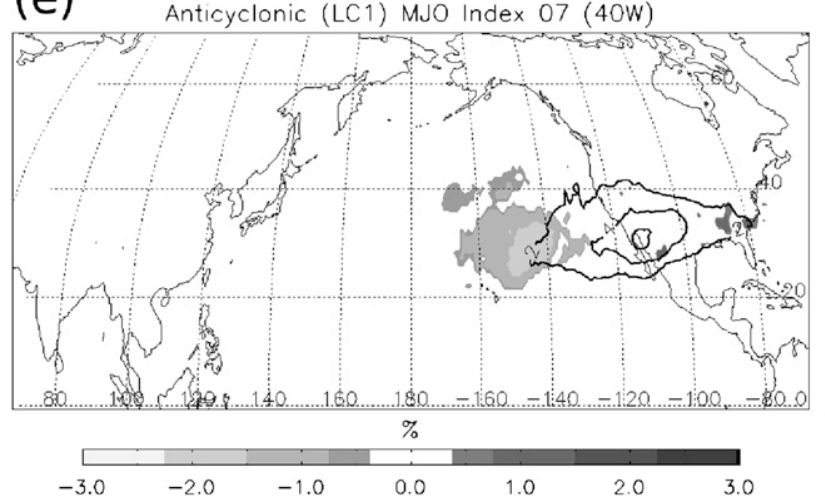

(b)

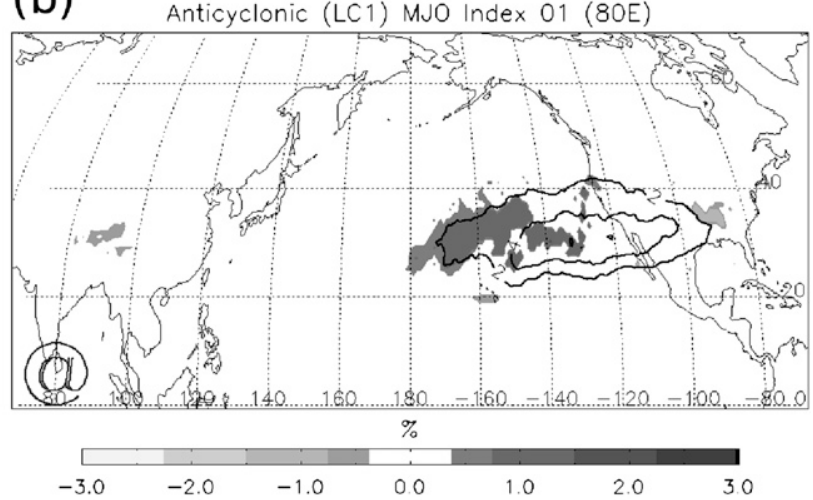

(d)

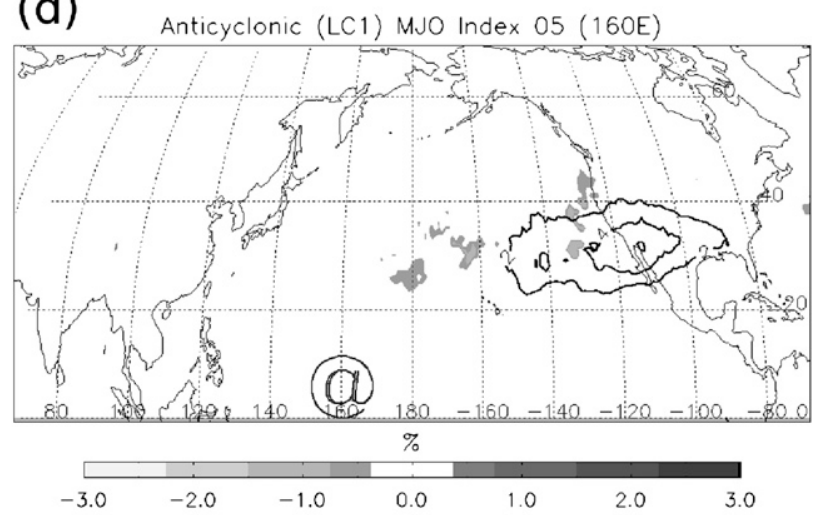

(f)

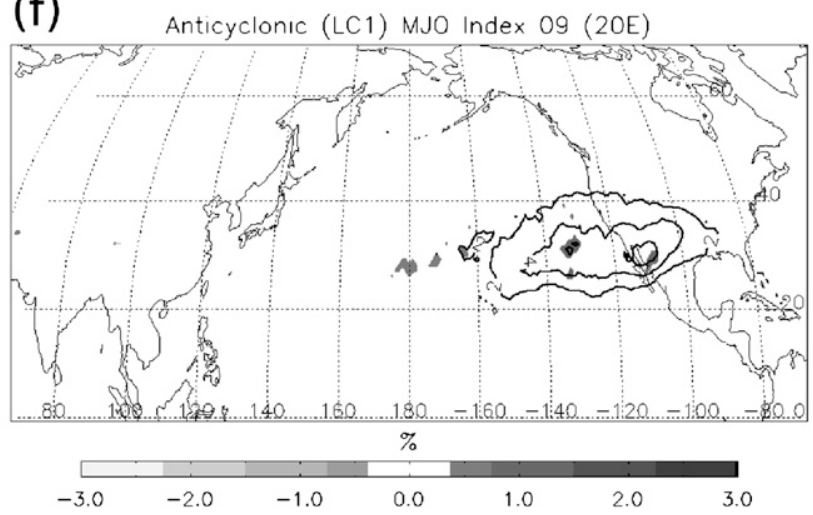

FIG. 3. As in Fig. 1, but for anticyclonic (LC1) wave breaking (\%) on the $330-\mathrm{K}$ isentropic surface. Contour interval is $2 \%$.

leads to a waveguide that is weak in the climatological mean. Matthews and Kiladis (1999a) note the proclivity for the equatorward propagation of extratropical waves during this phase of the MJO. Furthermore, they postulate these waves can provide a feedback onto the slowly varying diabatic heating field of the MJO via high-frequency convection induced by and ahead of the upper-level cyclonic disturbance. It is apparent from the composite analysis, as well as the MJO case study presented in section 4, that these equatorward-propagating waves are linked to LC1 wave breaking events. In contrast, the LC2 wave breaking observed over the western and central Pacific occurs on the north side of a strong zonal jet.

\section{c. Atmospheric block and surface cyclone frequency}

Wave breaking is intimately connected to synoptic-scale weather. As such, it is similarly valid to postulate that variability in more conventional weather parameters will also be observed over the Pacific basin in association with the atmospheric flow and wave breaking anomalies outlined above. Two such parameters, atmospheric blocking and surface cyclone frequency, are examined here. 
(a)

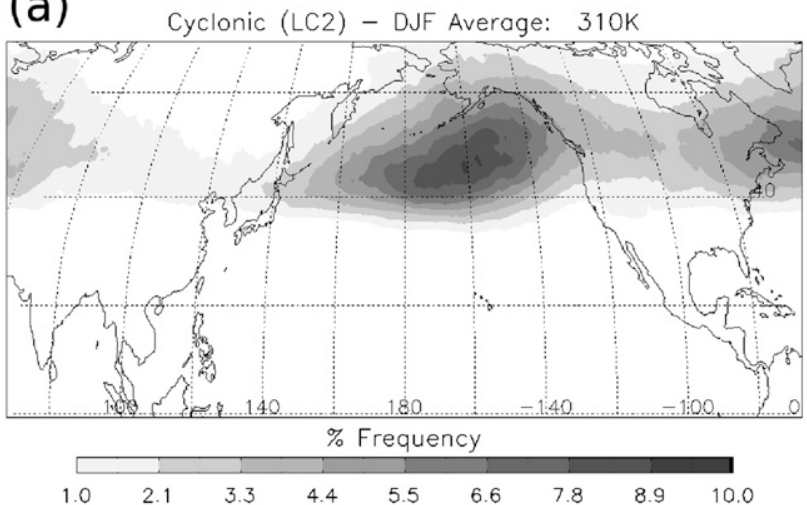

(c)

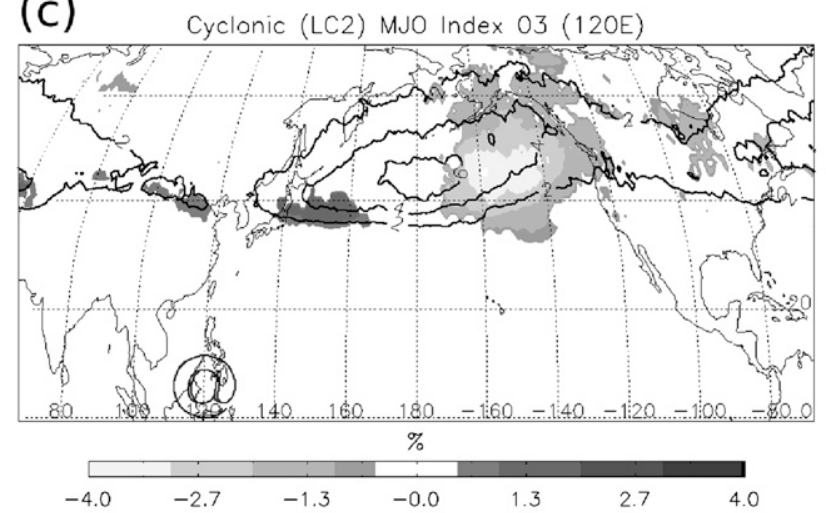

(e)

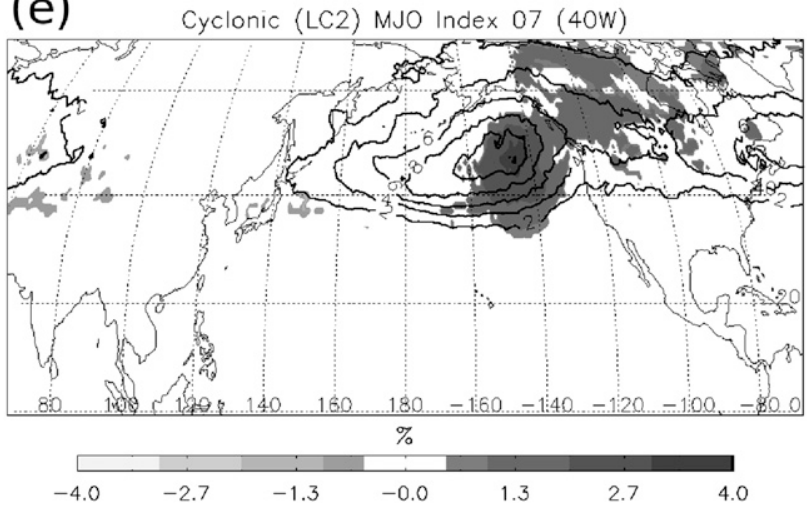

(b)

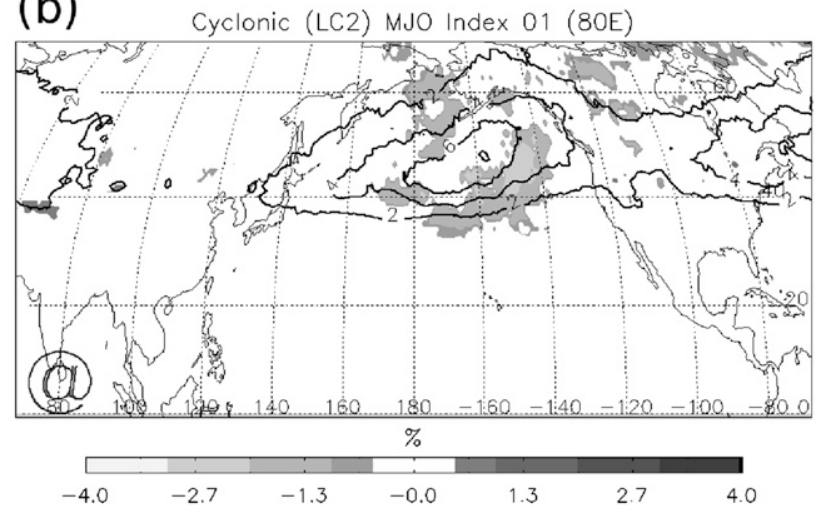

(d)

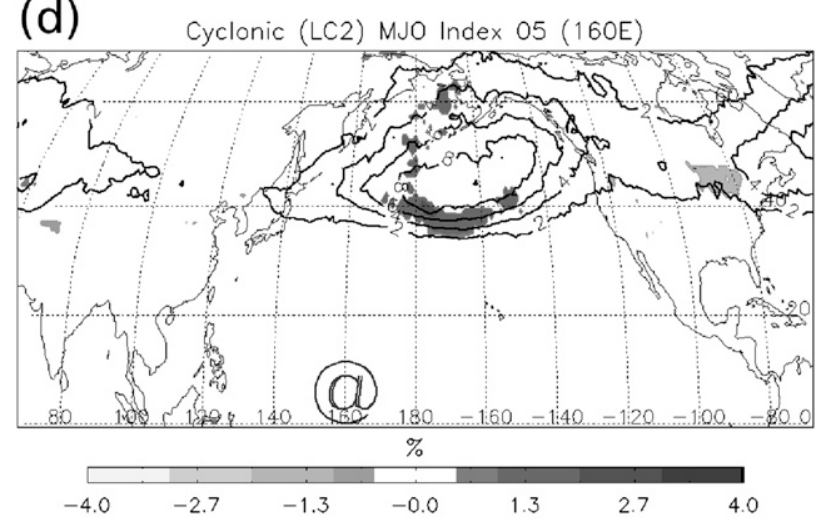

(f)

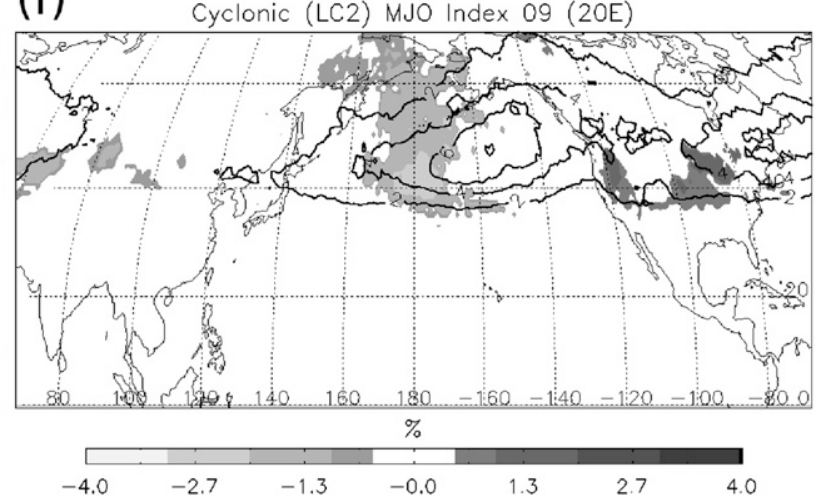

FIG. 4. As in Fig. 1, but for cyclonic (LC2) wave breaking (\%) on the $310-\mathrm{K}$ isentropic surface. Contour interval is $2 \%$.

\section{1) ATMOSPHERIC BLOCK FREQUENCY}

Atmospheric blocks represent semistationary, longliving (on the order of days to weeks) anticyclones that disrupt the predominant midlatitude westerly flow. They are generally associated with sustained subsidence and fair weather. The average and anomalous behavior of atmospheric blocks (as defined by Croci-Maspoli et al. 2007) during the composite MJO are presented in Fig. 5. The maximum in the DJF-average atmospheric block frequency is found in the eastern North Pacific, but there are relatively large values found across the central Pacific (Fig. 5a).
Consistent with the atmospheric flow anomalies, there is a statistically significant enhancement of atmospheric blocks in the central and eastern Pacific when the jet is retracted westward and there is a positive $500-\mathrm{hPa}$ height anomaly (Figs. 5b,c). Conversely, there is a reduced frequency of atmospheric blocks when the jet extends across the central Pacific and there is a negative 500-hPa height anomaly (Figs. 5d,e).

It is noteworthy that the enhanced blocking in the central Pacific during MJO index 1 (Fig. 1a) is concomitant with a reduction of LC2 wave breaking events upstream of the block. This is in contrast to the results of 
(a)

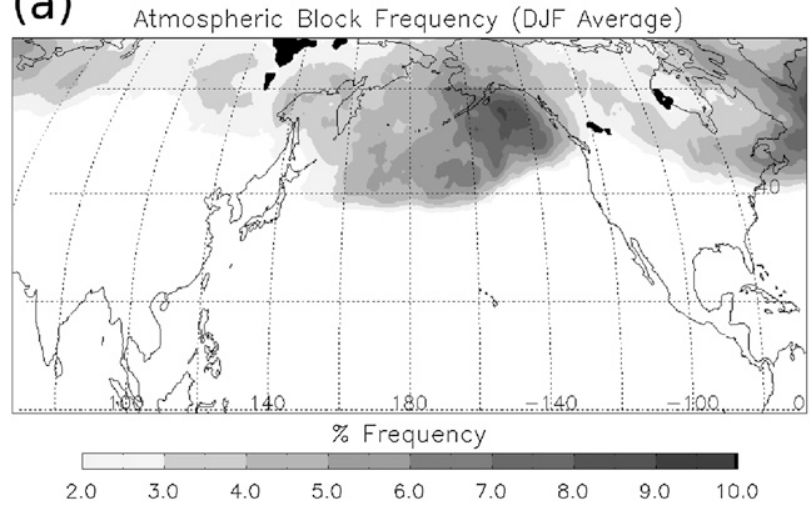

(c)

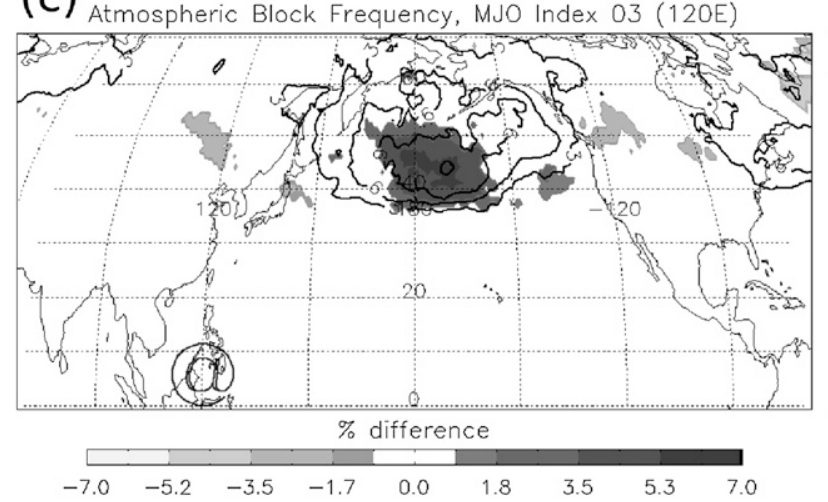

(e)

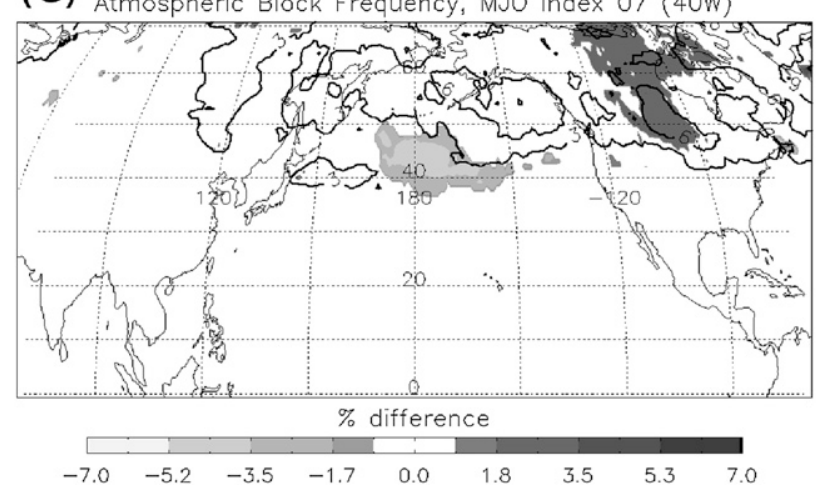

(b)

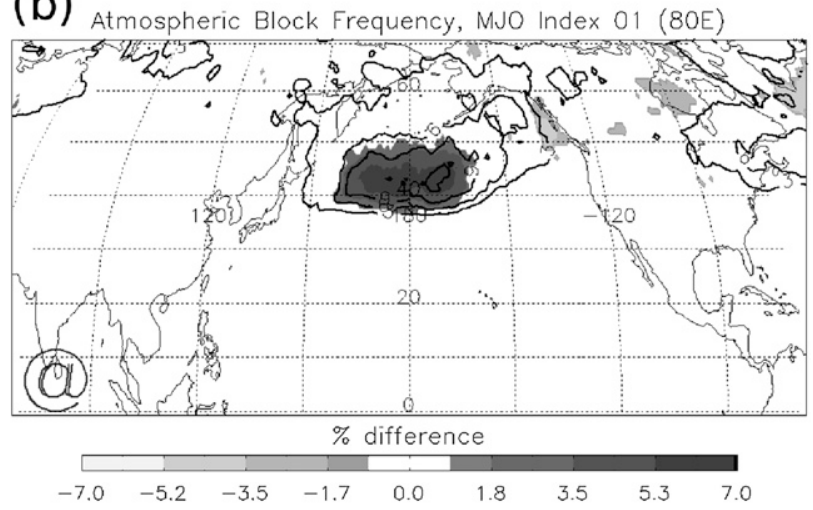

(d)

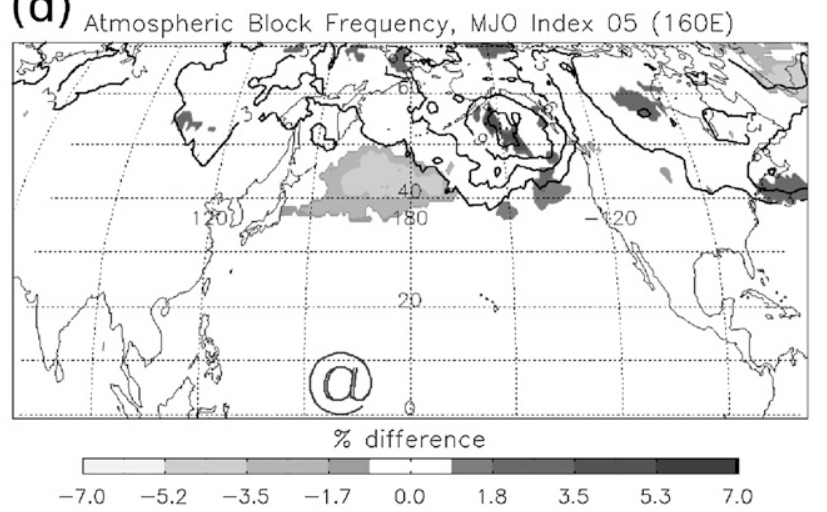

(f)

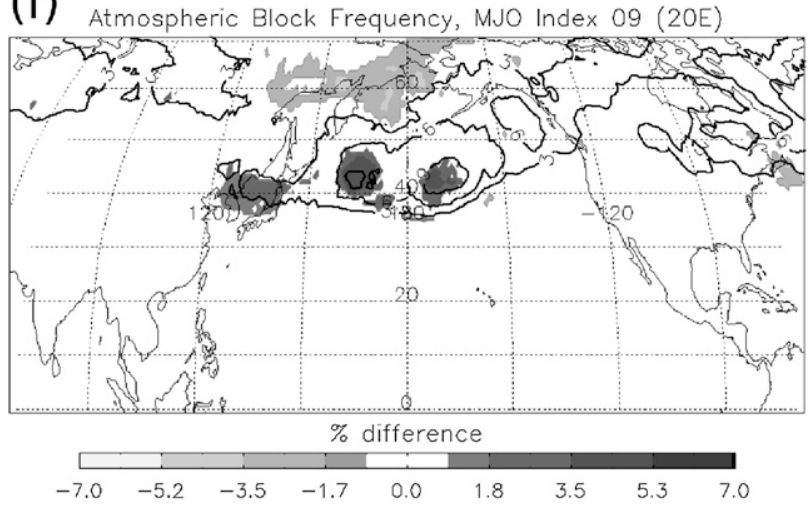

FIG. 5. As in Fig. 1, but for atmospheric block frequency (\%). Contour interval is $3 \%$.

Shutts (1983), who attributed these blocks to an increase in eddy driving. The relative lack of LC2 wave breaking events during this phase is, however, consistent with the results of Altenhoff et al. (2008). In their climatological analysis of the link between atmospheric blocks and wave breaking, they noted the number of blocks linked to LC2 wave breaking is smaller in the Pacific than in the Atlantic. Atmospheric blocks in the Pacific basin tend to be so-called omega blocks, which can form via processes other than synoptic-scale wave breaking (such as diabatic processes linked to larger-scale PV structures). By MJO index 3, however, a statistically significant increase in LC2 wave breaking upstream of enhanced atmospheric blocking is observed.

Also consistent with the study of Altenhoff et al. (2008), there is enhanced LC1 wave breaking to the south and southwest of the region of enhanced atmospheric block frequency (cf. Figs. 3 and 5b,c).

\section{2) SURFACE CYCLONE FREQUENCY}

The DJF surface cyclone frequency over the ERA-40 period exhibits a swath of enhanced cyclone frequency across the extratropical Pacific Ocean centered between $40^{\circ}-60^{\circ} \mathrm{N}$, generally referred to as the "storm track," with 
frequency values greater than $25 \%$. Breaking waves can be viewed as positive upper-level PV anomalies and have been found to be closely linked with surface weather (Hoskins et al. 1985). Therefore, modulations of wave breaking frequency and type such as those described above are likely to be reflected in such fields as surface cyclone frequency.

Given the proclivity of LC2 wave breaking to occur on lower isentropic surfaces, its attendant upper-level PV anomaly is closer to the surface and, hence, more likely to directly impact the surface flow. Orlanski (2003) has also found that LC2 wave breaking tends to occur in areas of stronger low-level baroclinicity. A direct comparison between the modulation of LC2 wave breaking during the evolution of the MJO and that of surface cyclone frequency (Figs. 4 and 6, respectively) suggests there is a robust connection between the two parameters. Suppressed (enhanced) LC2 wave breaking coincides well spatially with lower (higher) surface cyclone frequency. The temporal evolution illustrates the likelihood of a surface cyclone being present in the western (eastern) North Pacific is greater (lesser) when MJO convection is located in the warm pool region [Figs. 6b,c (Fig. 6e)]. These results compare favorably with lagged composites of SLP from Lin and Brunet (2009, see their Fig. 7). Moreover, surface cyclone activity is higher in the eastern Pacific during the later phases of the MJO. The latter signal is somewhat suppressed because of the statistical significance test: if the confidence level is lowered to $85 \%$, a wide swath of enhanced surface cyclone frequency is observed in the eastern Pacific.

\section{The 1993 MJO event}

A relatively coherent MJO event occurred in January and February 1993. This particular MJO event was chosen for further study not only because it is well behaved (in terms of its qualitative similarity to the composite MJO described above), but also because it is representative of the evolution of the numerous MJO events during the study period that the authors investigated.

Tropical convection associated with the 1993 MJO is observed over equatorial Africa (MJO index 9) during the first week of January 1993. By 13 January, tropical convection is active in the Indian Ocean (MJO indices 10 and 1). The MJO event subsequently evolves similarly to the composite picture, with approximately 5 days elapsing between respective MJO indices as the MJO propagates eastward until the ultimate demise of the event in mid-February.

Daily mean OLR from the CPC and the 200-hPa streamfunction anomaly (computed at 1200 UTC on the day in question) are shown at 5-day intervals for the 1993
MJO, beginning on 13 January (Fig. 7). In addition, the 250-hPa instantaneous total wind speed and the 2-PVU isoline on isentropic surfaces $(310-350 \mathrm{~K}, 20-\mathrm{K}$ interval) for select times are presented in Fig. 8. These plots are used to draw parallels between the composite evolution described above and the evolution of a distinct MJO event.

The Matsuno-Gill pattern is evident during the 1993 MJO event (see Fig. 7): a positive streamfunction anomaly (i.e., anticyclonic circulation anomaly) is generally present to the northwest of the organized MJO convection (represented by low OLR values). This is a consistent feature throughout the convectively active period of the 1993 MJO. On the northern flank of the streamfunction anomaly the meridional streamfunction gradient is increased, which is consistent with an enhanced zonal wind in this region. Again, the increased magnitude of the vertical wind shear that likely accompanies the locally strengthened tropopause-level jet suggests increased baroclinicity at this location through some depth of the troposphere.

\section{a. Overview of wave breaking events}

Wave breaking events during the 1993 MJO have been subjectively identified via an examination of the evolution of the 2-PVU isoline on the $310-350-\mathrm{K}$ isentropic surfaces. The same guidelines as those for the objective identification algorithm (Martius et al. 2007) are used; namely, a narrow connection to the stratospheric reservoir of high PV and the representative angle between the zonal direction and the meridionally elongated streamer.

The series of observed wave breaking events that occurred in the Pacific basin during the 1993 MJO event are presented in chronological order as follows:

- LC1 wave breaking in the central Pacific from 16 to 19 January (MJO index 1). The event is visible as a negative streamfunction anomaly (anomalous cyclonic circulation) centered on $15^{\circ} \mathrm{N}, 180^{\circ}$ and a meridional extension of the 350-K, 2-PVU isoline to the west of the date line in Figs. $7 \mathrm{~b}$ and $8 \mathrm{a}$, respectively. Convection associated with the breaking wave (low OLR values) is observed to the southeast of the streamfunction anomaly.

- LC1 wave breaking in the eastern Pacific from 22 to 25 January (MJO index 3 ). The event is visible in Figs. $7 \mathrm{c}$ and $8 \mathrm{~b}$ at approximately $10^{\circ} \mathrm{N}, 150^{\circ} \mathrm{W}$, with a similar pattern of streamfunction and OLR anomalies as with the previous LC1 wave breaking event.

- Two LC2 wave breaking events in the western and central North Pacific: 28-30 January (MJO index 4-5) centered at approximately $30^{\circ} \mathrm{N}, 150^{\circ} \mathrm{E}$ (Figs. $7 \mathrm{~d}$ and 8c) and 2-5 February (MJO index 5-6) centered at 
(a)

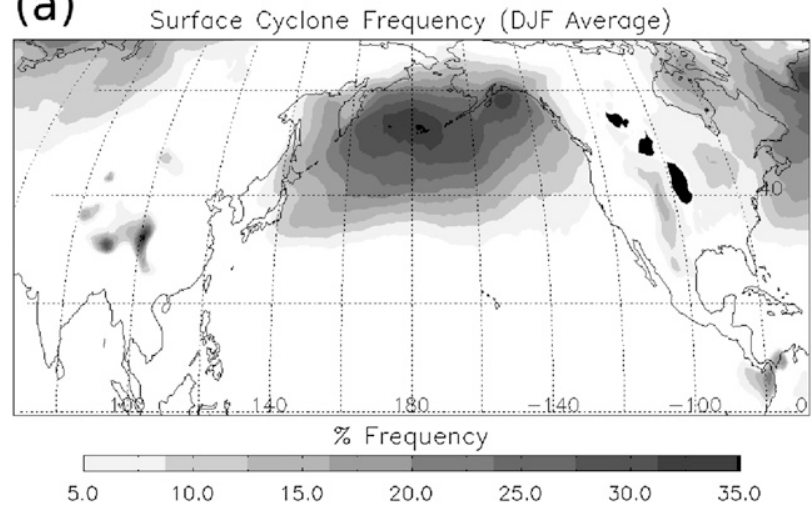

(c)

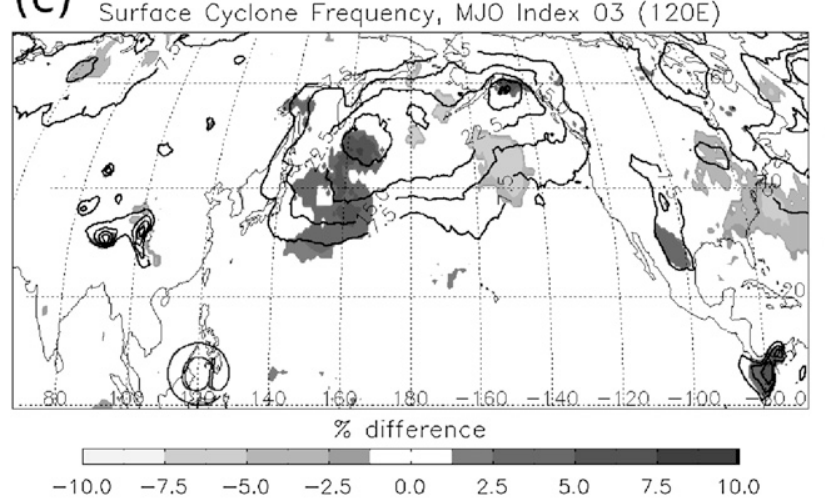

(e)

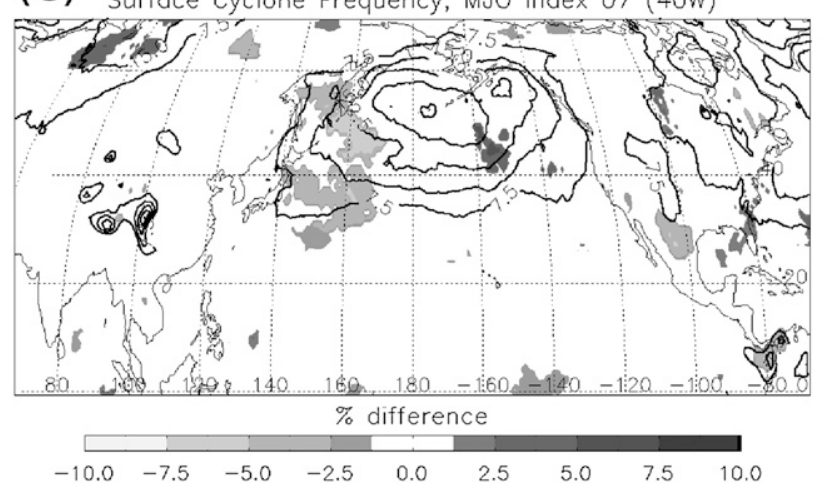

(b)

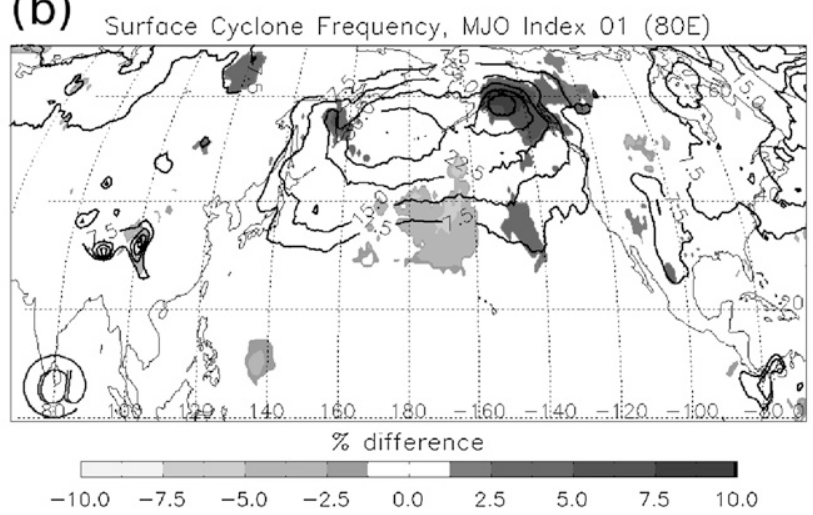

(d)

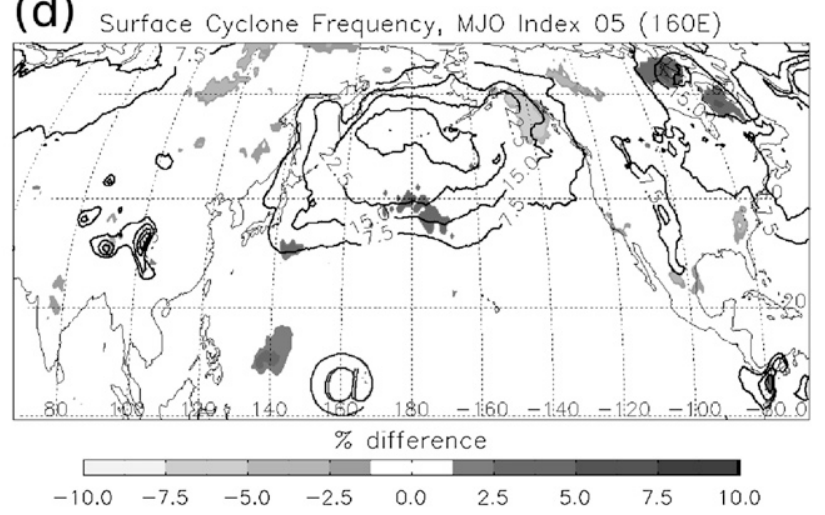

(f)

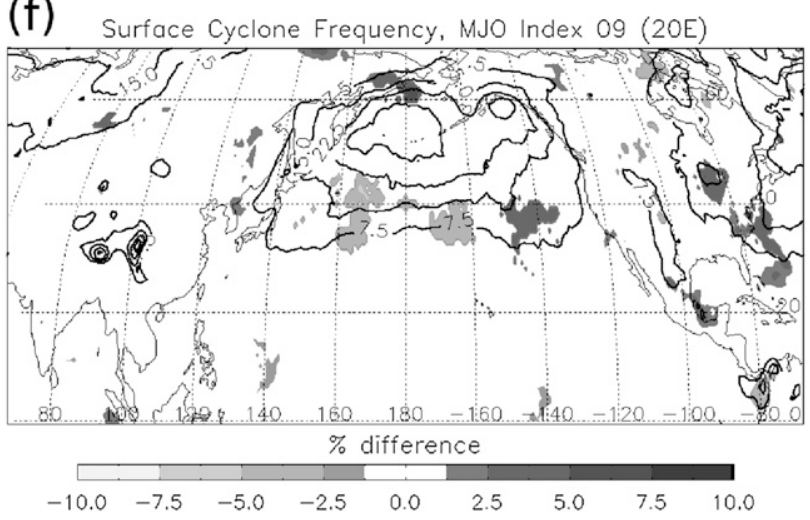

FIG. 6. As in Fig. 1, but for surface cyclone frequency (\%). Contour interval is $7.5 \%$.

about $35^{\circ} \mathrm{N}, 180^{\circ}$ (Fig. 7e). Both events are associated with a northward extension of a positive streamfunction anomaly and enhanced convection to the northwest of the center of the streamfunction anomaly.

- Multiple LC2 wave breaking events are subsequently observed in the eastern North Pacific between approximately 7 and 14 February (MJO indices 6-9).

The observed structure of the wave breaking events presented in Fig. 8 indicates that barotropic instability is not the dynamical mechanism responsible for the wave breaking. The phase tilt of the eddies with respect to the horizontal shear clearly illustrates that the breaking waves are imparting momentum to the jet rather than growing at the expense of the mean flow.

\section{b. Jet-wave breaking interactions}

It is instructive to take these wave breaking events and further investigate the relationship between the event itself and the evolving structure of the instantaneous jet. The first LC1 wave breaking event is evident at approximately $180^{\circ}-170^{\circ} \mathrm{E}$. It takes the form of a meridional extension to the south of the 2-PVU isolines on both 330 and $350 \mathrm{~K}$ (Fig. 8a), oriented from the northeast to southwest. A double jet structure comprised of an 
(a)
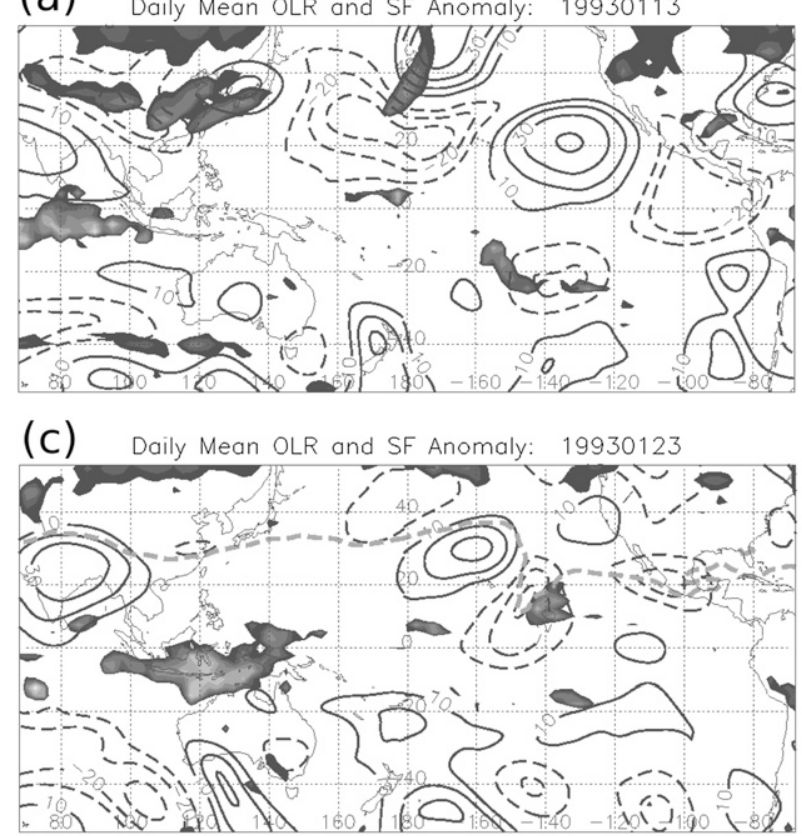

(e)

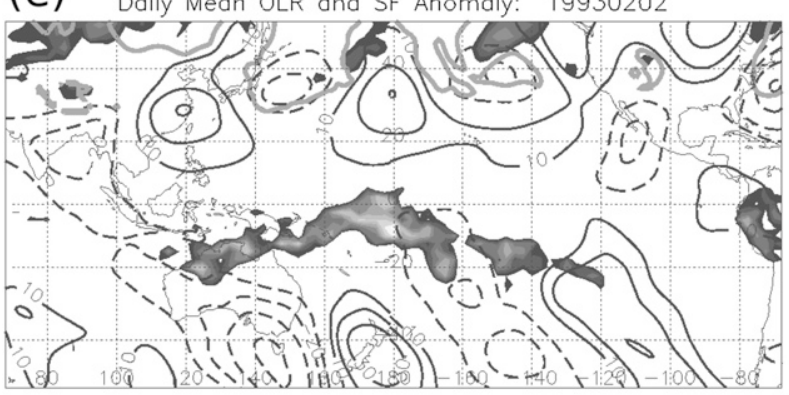

(b)

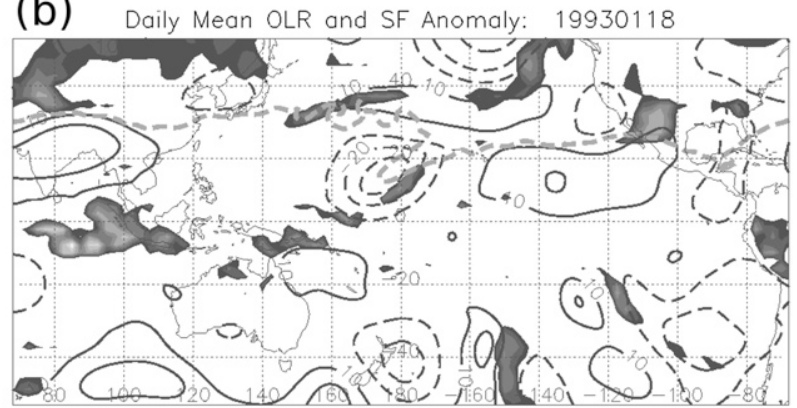

(d)

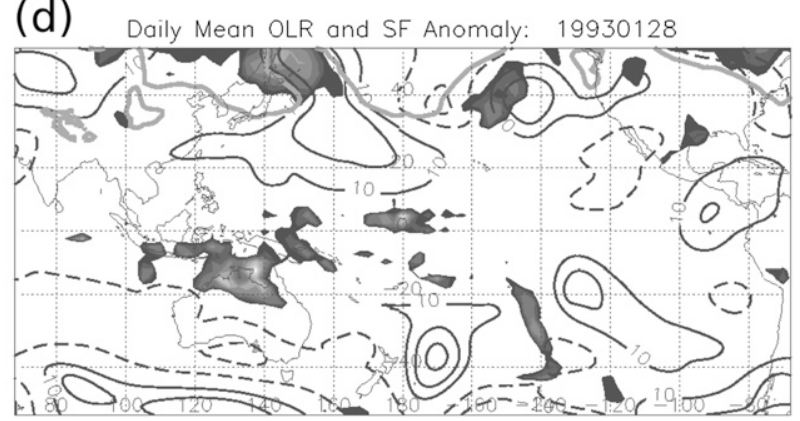

(f)

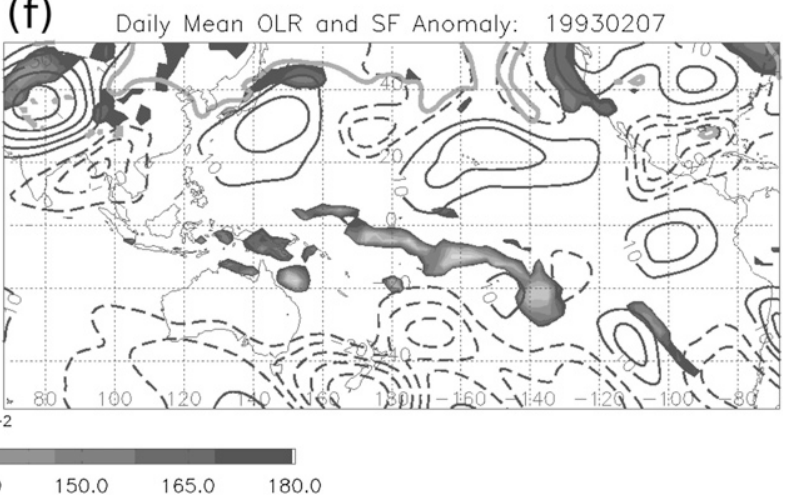

FIG. 7. Daily-average OLR (shading $\mathrm{W} \mathrm{m}^{-2}$ ) and streamfunction anomaly (at 1200 UTC) for the 1993 MJO event at (a) 13 Jan, (b) 18 Jan, (c) 23 Jan, (d) 28 Jan, (e) 2 Feb, and (f) 7 Feb. The 2-PVU isoline on $350 \mathrm{~K}[310 \mathrm{~K}]$ is shown as a gray dashed [solid] line in (b), (c) $[(\mathrm{d})-(\mathrm{f})]$.

upstream midlatitude jet and a downstream subtropical jet is associated with the event.

This picture provides a distinctly different impression than that attained from the climatological analysis for MJO index 1 (cf. Fig. 1b). When viewing solely the climatological data, one might imagine the presence of a single (midlatitude) jet retracted to the west. The actual situation is significantly more complex.

The core of the midlatitude jet is indeed retracted westward and shifted to the north over eastern Asia. It is likely that this northward displacement plays a seminal role in "selecting" an anticyclonic baroclinic life cycle (i.e., LC1 wave breaking). What is not apparent from the climatological analysis alone is the presence of a branch of the subtropical jet stream to the southeast of the midlatitude jet downstream of the wave breaking event. This double jet structure is common for LC1 wave breaking in general (Martius et al. 2007, see their Fig. 10c) and, more specifically, during this particular phase of the MJO.

A direct comparison of the climatological and case study information provides dynamical insight into the observed composite anomalies, highlighting the usefulness of using the two analyses in conjunction. Specifically with regards to the observed climatological $250-\mathrm{hPa}$ total wind speed anomalies (Fig. 1), it is now possible to ascribe the anomalies found in the central and eastern Pacific during MJO indices 1-3 (a positive-negative-positive tripole anomaly of the total wind speed oriented from the northwest to the southeast; Figs. 1b,c) to the presence of 
(a)

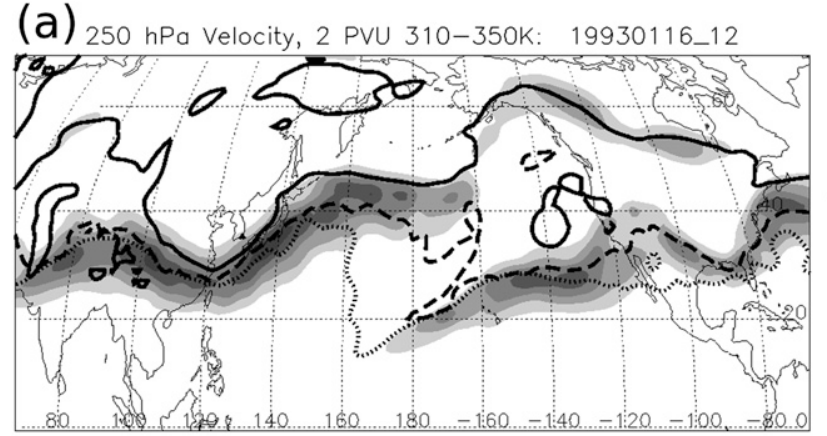

(c)

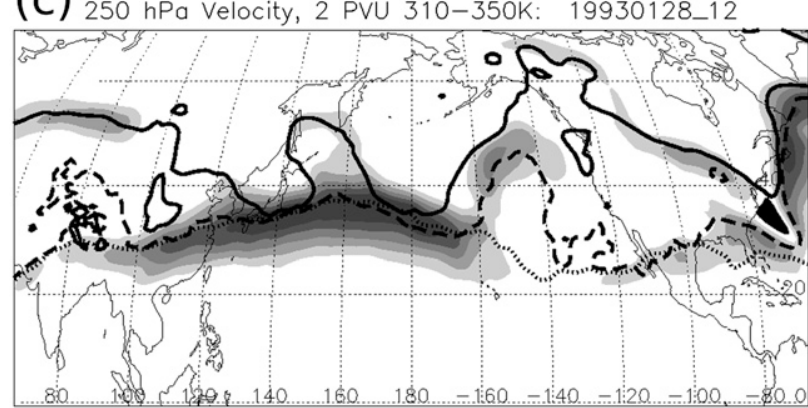

(b) $250 \mathrm{hPa}$ Velocity, 2 PVU 310-350K: 19930123_12

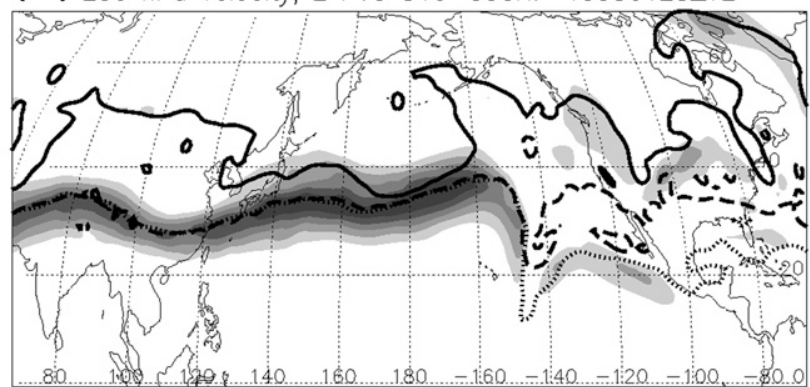

(d) $250 \mathrm{hPa}$ velocity, 2 PVU 310-350K: 19930205_12

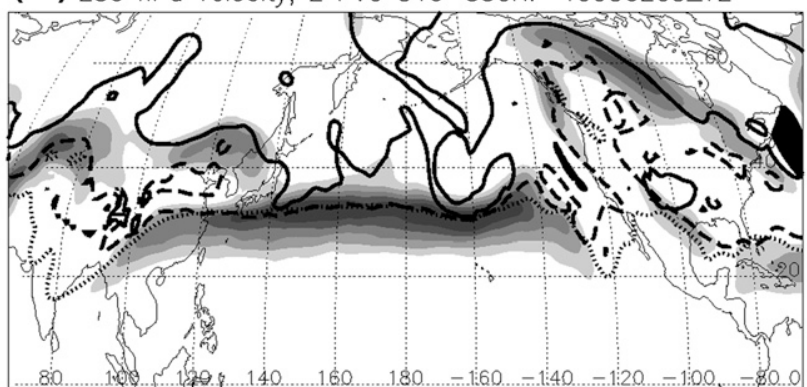

(e)

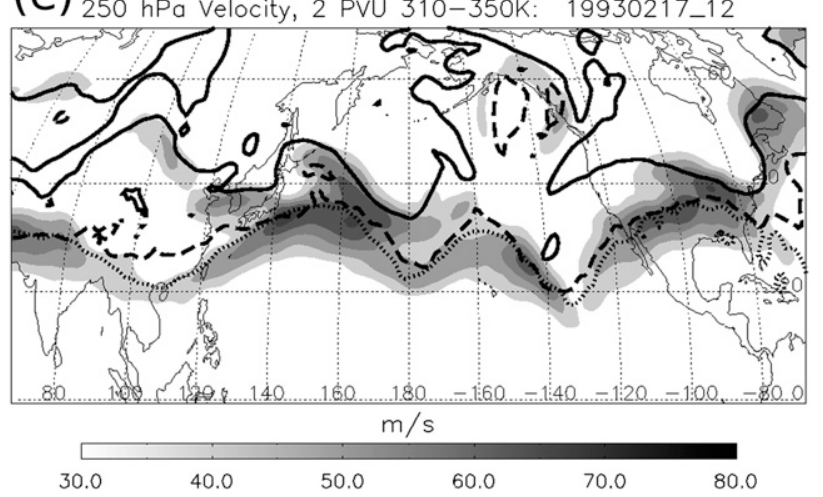

FIG. 8. Instantaneous 250-hPa total wind speed (shading) and the 2-PVU isoline on isentropic surfaces [310 (solid), 330 (dashed), and $350 \mathrm{~K}$ (dotted)] at (a) 1200 UTC 16 Jan, (b) 1200 UTC 23 Jan, (c) 1200 UTC 28 Jan, (d) 1200 UTC 5 Feb, and (e) 1200 UTC 17 Feb.

LC1 wave breaking and its attendant double jet structure, which mimics the composite anomalies (e.g., Fig. 8a). This information is not readily apparent from the climatological analysis alone.

At 1200 UTC 23 January (Fig. 8b), the midlatitude jet remains shifted northward over eastern Asia and extends to the east of the date line. The second LC1 wave breaking event outlined above is observed between the midlatitude jet and a remnant of the subtropical jet observed in Fig. 8a. Again, this picture is qualitatively consistent with the anomaly field for the relevant climatological result (MJO index 3, see Fig. 1c). Between the two wave breaking events, the midlatitude jet has extended farther to the east (as has the branch of the subtropical jet) and remains shifted to the north in the central and eastern Pacific, likely in part because of the momentum fluxes associated with the previous LC1 wave breaking event.

The first LC2 wave breaking event in the western North Pacific is depicted in Fig. 8c at 1200 UTC 28 January. It is found on the north side of a strong, narrow and zonally oriented midlatitude jet. Note that the wave breaking event is not occurring in the exit region of the midlatitude jet, its climatologically preferred location. Given the large local intensity of the jet, the relative position of the wave breaking event suggests it results from locally enhanced baroclinicity rather than being a repercussion of an upstream, meridional shift in the latitude of the jet axis. The wave breaking occurs in a region of large climatological baroclinicity associated with a land-sea contrast between Asia/Japan and the warm Kuroshio Ocean Current. 
By 1200 UTC 5 February (Fig. 8d), the single, zonally oriented midlatitude jet has extended a significant distance to the east of the date line and is displaced to the south (in comparison to the mean jet position) over eastern Asia. The latter likely predisposes the environment to cyclonic baroclinic life cycles. Consistent with this observation, the remnant of the second LC2 wave breaking event is visible as the wrapped up 310-K, 2-PVU isoline (centered at approximately $65^{\circ} \mathrm{N}, 180^{\circ}$ ). This picture compares well with the climatological result for MJO index 7 (Fig. 1e). It is at this time that the midlatitude jet attains is farthest extension to the east during the 1993 MJO event.

A significant undulation in the midlatitude jet is observed on 0000 UTC 17 February (Fig. 8e), near the end of the 1993 MJO event. One can also see the remnants of an LC2 wave breaking event in the northeast Pacific. Shortly after this time, the jet breaks down completely and the maximum jet intensity retreats to the western North Pacific.

\section{c. Synoptic-scale weather}

Other features of the $1993 \mathrm{MJO}$ are similar to that observed in the climatology. Daily values of the PNA index reveal a distinct shift from negative to positive values that occurs roughly from 25 to 29 January (MJO index 4-5). It is during this time that LC2 wave breaking is first observed on the north side of the jet in the east-central North Pacific. While not proving causality, this suggests that the LC2 wave breaking and baroclinic instability plays an integral role in the observed shift between the negative and positive phase of the PNA (C. Franzke, S. Feldstein, and S. Lee 2007, personal communication).

Three atmospheric blocks were found during the MJO event: (i) over the central and eastern North Pacific from 11 to 18 January (MJO indices 10-2), (ii) over the western and central North Pacific from 13 to 18 January (MJO indices 10-2), and (iii) a long-lasting block that slowly translated from the eastern North Pacific to North America from 29 January to 8 February (MJO indices 48 ). The timing and location of all blocks are qualitatively consistent with the climatology.

Of further note, LC1 wave breaking event number 1 (16-19 January) occurred on the southeastern flank of block (ii). The presence of LC1 wave breaking on the southeastern flank of an atmospheric block is consistent with both the composite analysis (Figs. $3 \mathrm{~b}$ and $5 \mathrm{~b}$ ) and the study of Altenhoff et al. (2008) who found the anticyclonic deformation field associated with a block can initiate LC1 wave breaking in this region. It also appears that a number of LC2 wave breaking events in the eastern Pacific may have played a role in sustaining block (iii), most likely via the diabatic depletion of PV at upper levels associated with the warm conveyor belt of extratropical cyclones (e.g., Croci-Maspoli and Davies 2009). The positioning of the respective features in the composite analysis (Figs. 4e, 5e, and 6e) is at least qualitatively consistent with this interpretation.

Surface cyclones were numerous during the 1993 MJO event. Qualitatively, the spatial and temporal variability in surface cyclone frequency diagnosed in the climatological analysis are found. During the early phases of the event, there is a tendency for increased (decreased) surface cyclone frequency in the western (eastern) North Pacific. This trend is reversed in the later stages of the MJO event, during which there are a large number of surface cyclones identified in the eastern Pacific.

A direct comparison between surface cyclones and wave breaking events shows that there are many instances when a surface cyclone is found in the absence of a breaking wave. In contrast, each of the LC2 wave breaking events identified is accompanied by a surface cyclone. These facts reiterate the robust connection between LC2 wave breaking events and the presence of surface cyclones. They also strengthen the argument that baroclinic instability most likely plays a role in the LC2 wave breaking on the north side of the strong jet in the western and central North Pacific during MJO indices 3-5.

\section{Discussion}

\section{a. Summary of results}

The present study uses ERA-40 data and a number of novel climatologies to examine the impacts of the MJO on the subtropical and extratropical atmosphere during the Northern Hemisphere winter in the Pacific basin from 1979 to 2002.

A direct Rossby wave response to the MJO tropical convection is identified. During the convectively active phase of the MJO, it takes the form of an upper-level anticyclone located to the north or northwest of the area of tropical convection. The repercussion of such a feature is a strengthened and northward-shifted, tropopause-level jet on the northern flank of the anticyclone, a situation that likely predisposes the atmosphere for an anticyclonic baroclinic life cycle. Given its direct connection to the tropical convection, this feature propagates to the east along with the MJO.

This mechanism alone, however, is insufficient to account for all the observed changes of the tropopause level flow. Given that significant changes in the subtropical and extratropical flow can impact wave breaking behavior and that a wave breaking event can, in turn, impact the structure of the jet, it is dynamically meaningful to examine the variability of wave breaking and its relationship to the observed subtropical and extratropical flow anomalies. Statistically significant anomalies in the type, 
amount, and location of wave breaking events are found. Significant variability of atmospheric blocking and surface cyclone frequencies are also diagnosed.

The combination of climatological and case study analyses presented herein provide a comprehensive and coherent picture of the time-dependent state of the subtropical and extratropical atmosphere during an evolving MJO event.

\section{b. Is wave breaking fundamental to the observed changes in the subtropical and extratropical flow?}

The results of this work provide intriguing evidence that wave breaking along the dynamical tropopause may play a seminal role in the documented evolution of the subtropical and extratropical flow during the MJO. The fact remains that it is difficult to decompose wavemean flow interactions into cause and effect. However, we believe the robust nature of the interaction found herein allows for a conceptual picture of certain aspects of the observed evolution.

A schematic of the observed changes is presented in Fig. 9 and described below. The schematic attempts to describe the general characteristics of the atmosphere in response to an evolving MJO event. The top, middle, and bottom panels represent the atmospheric state during MJO indices 10-2, 3-5, and 6-8, respectively.

\section{1) FIG. 9 (TOP PANEL)}

MJO tropical convection is in the Indian Ocean. Characteristic of the convectively active phases of the MJO (indices 10,1-5), the direct Rossby wave, Matsuno-Gill response to the convection generates an upper-level anticyclone to the northwest of the area of maximum tropical heating. Consistent with the enhanced meridional streamfunction gradient on the northern flank of the positive streamfunction anomaly, the jet is strengthened in this region and shifted to the north.

The northern position of the jet over eastern Asia predisposes the atmosphere to anticyclonic baroclinic life cycles and LC1 wave breaking is found in the west-central Pacific. The LC1 wave breaking is associated with (i) a double jet configuration [which accounts for the observed tripole composite jet anomalies in the central Pacific (see Fig. 1b)]; (ii) momentum fluxes that shift the jet to the north in the central Pacific; and (iii) induced subtropical and tropical convection on the southeastern periphery of the breaking wave. The latter feature is of note, as the wave breaking-induced convection may project back onto the MJO diabatic heating field and thereby aid the eastward propagation of the MJO (Matthews and Kiladis 1999a).

During this phase, there is higher probability of an atmospheric block in the western and central North Pacific and a relative absence of surface cyclones.
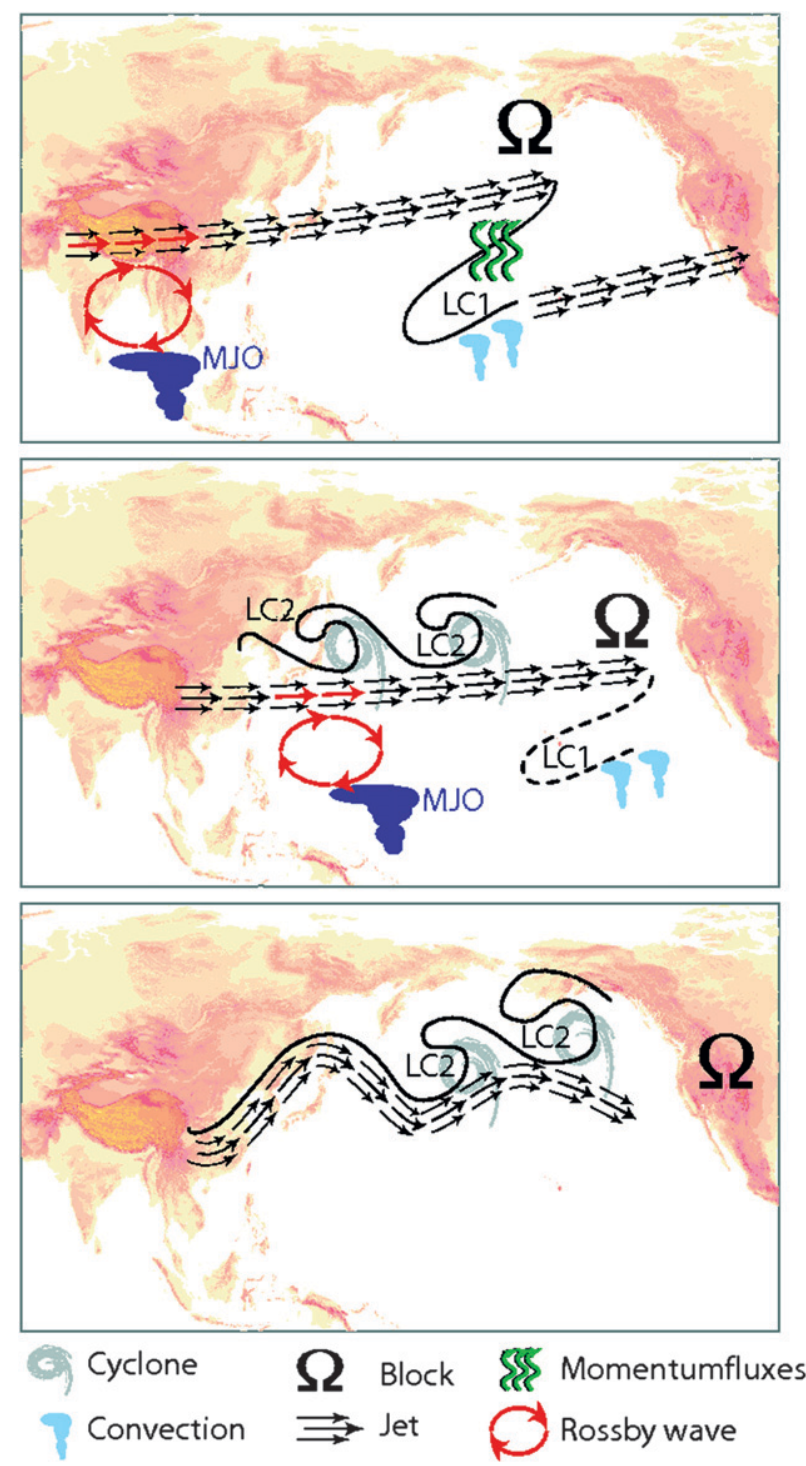

FIG. 9. Schematic representation of the MJO life cycle described in detail in the text. CPC MJO indices (top) 10-2, (middle) 3-5, and (bottom) 6-8. The solid and dashed black contours represent the dynamical tropopause on a representative potential temperature surface. (middle) Dashed contour precedes the solid contour in time.

\section{2) Fig. 9 (MIDDLE PANEL)}

The jet maximum extends to the east in conjunction with the eastward propagation of the MJO tropical convection, now found over the Maritime Continent and the warm pool region. The jet remains shifted to the north over eastern Asia/western Pacific and in the central Pacific due to the direct Rossby wave response and the momentum fluxes associated with the previous LC1 wave breaking, respectively. Enhanced LC1 wave breaking, with similar characteristics as described for the top 
panel, is observed in the central and eastern Pacific to the east of previous LC1 wave breaking. The probability of an atmospheric block in the central North Pacific remains relatively high, but has shifted to the east.

Subsequent to the LC1 wave breaking in the eastern Pacific, the likelihood of LC2 wave breaking increases over the western and central Pacific on the north side of the locally narrow and strong jet. Consistent with the tendency for LC2 wave breaking events to have a surface signature, an enhanced probability of a surface cyclone accompanies the LC2 wave breaking in both time and space.

The enhanced frequency of LC2 wave breaking events is not the result of a meridional shift in the upstream jet position. We believe that changes in the local environment, at least partially due to the direct response of the atmosphere to the MJO tropical convection, lead to a situation that is susceptible to baroclinic instability and conducive to both wave breaking and surface cyclone development on the northern flank of the locally strong jet. With respect to the breaking waves as observed in this study, there is no evidence of barotropic instability.

The collocation of LC2 wave breaking and the subsequent rapid, observed transition that occurs in the central North Pacific between MJO indices 4 and 6 suggests a direct link between the two. It is during and shortly after the LC2 wave breaking events that the PNA-like signal changes sign (over an approximate 10-day period). While not explicitly proven herein, we believe the LC2 wave breaking is integral to this process (C. Franzke, S. Feldstein, and S. Lee 2007, personal communication).

\section{3) Fig. 9 (BOTTOM PANEL)}

Subsequent to the propagation of the MJO east of the date line and the cessation of MJO convection, the jet attains its farthest eastward extension. Over central and eastern Asia, the jet is shifted to the south and the situation is predisposed to cyclonic baroclinic life cycles. The relatively strong jet constitutes a waveguide spanning the central Pacific and enhanced LC2 wave breaking has extended to the jet exit region in the eastern North Pacific. Increased surface cyclone frequency continues to accompany the LC2 wave breaking and enhanced atmospheric block activity is now located over central North America.

Shortly after this time and in the continued absence of the direct Rossby wave, Matsuno-Gill response to tropical convection, the jet becomes noticeably less zonal. Ultimately, the jet breaks down and retreats westward, completing the full MJO life cycle.

\section{c. Concluding remarks}

The results presented herein constitute an important step toward a better understanding of the observed variability in the subtropics and extratropics in the Pacific basin during an evolving MJO event. While intriguing, much work remains to be done. Specifically, it is necessary to more directly assess the cause-effect nature of the wave-mean flow interaction between breaking waves and the subtropical and extratropical flow. A more quantitative analysis, possibly via in depth observational and/ or idealized modeling studies, would be valuable.

These results also shed light on the issue of predictability. Numerous researchers have indicated that the MJO may be accompanied by increased predictability in the subtropics and extratropics (e.g., Waliser et al. 2003; Cassou 2008; Lin and Brunet 2009). Cassou (2008) conducted a similar study to that herein, investigating the link between the MJO and the North Atlantic Oscillation. Via the use of a simple statistical model, he found that for approximately $70 \%$ of the cases it was possible to successfully forecast the sign of the NAO given knowledge of the previous 12-day MJO phase. While not explicitly explored here, the robust nature of the observed response of the subtropical and extratropical atmosphere to the MJO indicates that similar predictability exists for the Pacific basin. As rightly identified by Cassou (2008), however, this increased predictability will not be fully realized until today's forecast models can properly simulate not only tropical MJO dynamics but also the tropicalextratropical interactions that are integral to the evolution of the atmosphere on the global scale.

Acknowledgments. The authors thank the NCCR for project financing, Meteoswiss for access to ERA-40 data, Cornelia Schwierz and Mischa Croci-Maspoli for access to their blocking climatology, Heini Wernli and Cornelia Schwierz for access to their surface cyclone climatology, Huw Davies for his advice and support, and the reviewers for their thoughtful and constructive comments.

\section{REFERENCES}

Akahori, K., and S. Yoden, 1997: Zonal flow vacillation and bimodality of baroclinic eddy life cycles in a simple global circulation model. J. Atmos. Sci., 54, 2349-2361.

Altenhoff, A. M., O. Martius, M. Croci-Maspoli, C. Schwierz, and H. C. Davies, 2008: Linkage of atmospheric blocks and synoptic-scale Rossby waves: A climatological analysis. Tellus, 60, 1053-1063.

Appenzeller, C., and H. C. Davies, 1992: Structure of stratrospheric intrusions into the tropopause. Nature, 358, 570-572.

Barlow, M., A. Hoell, and F. Colby, 2007: Examining the wintertime response to tropical convection over the Indian Ocean by modifying convective heating in a full atmospheric model. Geophys. Res. Lett., 34, L19702, doi:10.1029/2007GL030043.

Benedict, J., S. Lee, and S. Feldstein, 2004: Synoptic view of the North Atlantic oscillation. J. Atmos. Sci., 61, 121-144. 
Cassou, C., 2008: Intraseasonal interaction between the MaddenJulian Oscillation and the North Atlantic Oscillation. Nature, 455, 523-527, doi:10.1038/nature07286.

Croci-Maspoli, M., and H. C. Davies, 2009: Key dynamical features of the 2005/06 European winter. Mon. Wea. Rev., 137, 664-678.

—, C. Schwierz, and H. C. Davies, 2007: A multifaceted climatology of atmospheric blocking and its recent linear trend. Climate Dyn., 20, 633-649.

Dole, R. M., and N. D. Gordon, 1983: Persistent anomalies of the extratropical Northern Hemisphere wintertime circulation: Geographical distribution and regional persistence characteristics. Mon. Wea. Rev., 111, 1567-1586.

Edmon, H. J., B. J. Hoskins, and M. E. McIntyre, 1980: EliassenPalm cross sections for the troposphere. J. Atmos. Sci., 37, 2600 2616.

Esler, J. G., and P. H. Haynes, 1999: Baroclinic wave breaking and the internal variability of the tropospheric circulation. J. Atmos. Sci., 56, 4014-4031.

Ferranti, L., T. N. Palmer, F. Molteni, and E. Klinker, 1990: Tropical-extratropical interaction associated with the 30-60 day oscillation and its impact on medium and extended range prediction. J. Atmos. Sci., 47, 2177-2199.

Franzke, C., S. Lee, and S. B. Feldstein, 2004: Is the North Atlantic Oscillation a breaking wave? J. Atmos. Sci., 61, 145-160.

Gill, A. E., 1980: Some simple solutions for heat-induced tropical circulation. Quart. J. Roy. Meteor. Soc., 106, 447-462.

Hendon, H. H., and M. L. Salby, 1994: The life cycle of the MaddenJulian oscillation. J. Atmos. Sci., 51, 2225-2237.

Higgins, R. W., and K. C. Mo, 1997: Presistent North Pacific circulation anomalies and the tropical intraseasonal oscillation. Climate Dyn., 10, 223-244.

Hoskins, B. J., I. N. James, and G. H. White, 1983: The shape, propagation and mean-flow interaction of large-scale weather systems. J. Atmos. Sci., 40, 1595-1612.

_ M. E. McIntyre, and A. W. Robertson, 1985: On the use and significance of isentropic potential vorticity maps. Quart. J. Roy. Meteor. Soc., 111, 877-946.

Hsu, H., 1996: Global view of the intraseasonal oscillation during northern winter. Climate Dyn., 9, 2386-2406.

Jin, F., and B. J. Hoskins, 1995: The direct response to tropical heating in a baroclinic atmosphere. J. Atmos. Sci., 52, 307-319.

Kiladis, G. N., and K. M. Weickmann, 1992: Circulation anomalies associated with tropical convection during northern winter. Mon. Wea. Rev., 120, 1900-1923.

Knutson, T. R., and K. M. Weickmann, 1987: 30-60 day atmospheric oscillations: Composite life cycles of convection and circulation anomalies. Mon. Wea. Rev., 115, 1407-1436.

Liebmann, B., and C. A. Smith, 1996: The description of a complete (interpolated) outgoing longwave radiation dataset. Bull. Amer. Meteor. Soc., 77, 1275-1277.

Lin, H., and G. Brunet, 2009: The influence of the Madden-Julian oscillation on Canadian wintertime surface air temperature. Mon. Wea. Rev., 137, 2250-2262.

Lupo, A. R., and P. J. Smith, 1995: Planetary and synopticscale interactions during the life-cycle of a midlatitude blocking anticyclone over the North Atlantic. Tellus, 47, 575596.

Madden, R. A., and P. R. Julian, 1972: Description of global-scale circulation cells in the tropics with a 40-50-day period. $J$. Atmos. Sci., 29, 1109-1123.

, and - 1994: Observations of the 40-50-day tropical oscillation-A review. Mon. Wea. Rev., 122, 814-837.
Magnusdottir, G., and P. H. Haynes, 1996: Wave activity diagnostics applied to baroclinic waves. J. Atmos. Sci., 53, 23172353.

Martius, O., C. Schwierz, and H. C. Davies, 2007: Breaking waves at the tropopause in the wintertime Northern Hemisphere: Climatological analyses of the orientation and the theoretical LC1/2 classification. J. Atmos. Sci., 64, 2576-2592.

Matsuno, T., 1966: Quasi-geostrophic motions in the equatorial area. J. Meteor. Soc. Japan, 44, 25-43.

Matthews, A. J., and G. N. Kiladis, 1999a: Interactions between ENSO, transient circulation, and tropical convection over the Pacific. Climate Dyn., 12, 3062-3086.

$\longrightarrow$, and - 1999b: The tropical-extratropical interaction between high-frequency transients and the Madden-Julian oscillation. Mon. Wea. Rev., 127, 661-677.

— B. J. Hoskins, and M. Masutani, 2004: The global response to tropical heating in the Madden-Julian oscillation during the northern winter. Quart. J. Roy. Meteor. Soc., 130, 19912011.

McIntyre, M. E., and T. N. Palmer, 1983: Breaking planetary waves in the stratosphere. Nature, 305, 593-600.

Mori, M., and M. Watanabe, 2008: The growth and triggering mechanism of the PNA: A MJO-PNA coherence. J. Meteor. Soc. Japan, 86, 213-236.

Orlanski, I., 2003: Bifurcation in eddy life cycles: Implications for storm track variability. J. Atmos. Sci., 60, 993-1023.

Rex, D., 1950: Blocking action in the middle troposphere and its effect upon regional climate. I: An aerological study of blocking. Tellus, 2, 169-211.

Riviere, G., 2009: Effect of latitudinal variations in low-level baroclinicity on eddy life cycles and upper-tropospheric wavebreaking processes. J. Atmos. Sci., 66, 1569-1592.

_ , and I. Orlanski, 2007: Characteristics of the Atlantic stormtrack eddy activity and its relation with the North Atlantic Oscillation. J. Atmos. Sci., 64, 241-266.

Scherrer, S. C., M. Croci-Maspoli, C. Schwierz, and C. Appenzeller, 2006: Two-dimensional indices of atmospheric blocking and their statistical relationship with winter climate patterns in the Euro-Atlantic region. Int. J. Climatol., 26, 233-249.

Schubert, S. D., and C. Park, 1991: Low-frequency intraseasonal tropical-extratropical interactions. J. Atmos. Sci., 48, 629650.

Schwierz, C., M. Croci-Maspoli, and H. C. Davies, 2004: Perspicacious indicators of atmospheric blocking. Geophys. Res. Lett., 31, L06125, doi:10.1029/2003GL019341.

Shutts, G. J., 1983: The propagation of eddies in diffluent jetstreams: Eddy vorticity forcing of 'blocking' flow fields. Quart. J. Roy. Meteor. Soc., 109, 737-761.

Simmons, A. J., 1982: The forcing of stationary wave motion by tropical diabatic heating. Quart. J. Roy. Meteor. Soc., 108, 503-534.

_ J. M. Wallace, and G. W. Branstator, 1983: Barotropic wave propagation and instability, and atmospheric teleconnection patters. J. Atmos. Sci., 40, 1363-1392.

Strong, C., and G. Magnusdottir, 2008: Troposheric Rossby wave breaking and the NAO/NAM. J. Atmos. Sci., 65, 28612876.

Swanson, K. L., 2000: Stationary wave accumulation and the generation of low-frequency variability on zonally varying flows. J. Atmos. Sci., 57, 2262-2280.

Thorncroft, C. D., B. J. Hoskins, and M. J. McIntyre, 1993: Two paradigms of baroclinic-wave life-cycle behavior. Quart. J. Roy. Meteor. Soc., 119, 17-55. 
Uppala, S. M., and Coauthors, 2006: The ERA-40 Re-Analysis. Quart. J. Roy. Meteor. Soc., 131, 2961-3012.

Vallis, G., and E. Gerber, 2008: Local and hemispheric dynamics of the North Atlantic oscillation, annular patterns and the zonal index. Dyn. Atmos. Oceans, 44, 184-212.

Waliser, D. E., K. M. Lau, W. Stern, and C. Jones, 2003: Potential predictability of the Madden-Julian oscillation. Bull. Amer. Meteor. Soc., 84, 33-50.

Wernli, H., and C. Schwierz, 2006: Surface cyclones in the ERA-40 dataset (1958-2001). Part I: Novel identification method and global climatology. J. Atmos. Sci., 63, 2486-2507.
- and M. Sprenger, 2007: Identification and ERA-15 climatology of potential vorticity streamers and cutoffs near the extratropical tropopause. J. Atmos. Sci., 64, 1569-1602.

Woollings, T., B. Hoskins, M. Blackburn, and P. Berrisford, 2008: A new Rossby wave breaking interpretation of the North Atlantic Oscillation. J. Atmos. Sci., 65, 609-626.

Yang, S., and P. J. Webster, 1990: The effect of summer tropical heating on the location and intensity of the extratropical westerly jet. J. Geophys. Res., 95, 18 705-18 721.

Zhang, C., 2005: Madden-Julian Oscillation. Rev. Geophys., 43, RG2003, doi:10.1029/2004RG000158. 